\title{
Measuring naturally acquired immune responses to candidate malaria vaccine antigens in Ghanaian adults
}

\author{
Daniel Dodoo', Michael R Hollingdale², Dorothy Anum, Kwadwo A Koram², Ben Gyan', \\ Bartholomew D Akanmori, ${ }^{13}$, Josephine Ocran ${ }^{1}$, Susan Adu-Amankwah¹, Harini Geneshan ${ }^{4}$, Esteban Abot ${ }^{4}$, \\ Jennylyn Legano ${ }^{4}$, Glenna Banania ${ }^{4}$, Renato Sayo ${ }^{4}$, Donald Brambilla ${ }^{5}$, Sanjai Kumar ${ }^{6}$, Denise L Doolan ${ }^{8}$, \\ William $O$ Rogers ${ }^{1,7}$, Judith Epstein ${ }^{4}$, Thomas L Richie ${ }^{4}$ and Martha Sedegah ${ }^{4 *}$
}

\begin{abstract}
Background: To prepare field sites for malaria vaccine trials, it is important to determine baseline antibody and T cell responses to candidate malaria vaccine antigens. Assessing T cell responses is especially challenging, given genetic restriction, low responses observed in endemic areas, their variability over time, potential suppression by parasitaemia and the intrinsic variability of the assays.

Methods: In Part A of this study, antibody titres were measured in adults from urban and rural communities in Ghana to recombinant Plasmodium falciparum CSP, SSP2/TRAP, LSA1, EXP1, MSP1, MSP3 and EBA175 by ELISA, and to sporozoites and infected erythrocytes by IFA. Positive ELISA responses were determined using two methods. T cell responses to defined CD8 or CD4 T cell epitopes from CSP, SSP2/TRAP, LSA1 and EXP1 were measured by ex vivo IFN- $\gamma$ ELISpot assays using HLA-matched Class I- and DR-restricted synthetic peptides. In Part B, the reproducibility of the ELISpot assay to CSP and AMA1 was measured by repeating assays of individual samples using peptide pools and low, medium or high stringency criteria for defining positive responses, and by comparing samples collected two weeks apart.
\end{abstract}

Results: In Part A, positive antibody responses varied widely from 17\%-100\%, according to the antigen and statistical method, with blood stage antigens showing more frequent and higher magnitude responses. ELISA titres were higher in rural subjects, while IFA titres and the frequencies and magnitudes of ex vivo ELISpot activities were similar in both communities. DR-restricted peptides showed stronger responses than Class I-restricted peptides. In Part B, the most stringent statistical criteria gave the fewest, and the least stringent the most positive responses, with reproducibility slightly higher using the least stringent method when assays were repeated. Results varied significantly between the two-week time-points for many participants.

Conclusions: All participants were positive for at least one malaria protein by ELISA, with results dependent on the criteria for positivity. Likewise, ELISpot responses varied among participants, but were relatively reproducible by the three methods tested, especially the least stringent, when assays were repeated. However, results often differed between samples taken two weeks apart, indicating significant biological variability over short intervals.

\footnotetext{
* Correspondence: martha.sedegah@med.navy.mil

${ }^{4}$ US Military Malaria Vaccine Program, Naval Medical Research Center, Silver Spring, MD 20910, USA

Full list of author information is available at the end of the article
} 


\section{Background}

Naturally-acquired immune responses to Plasmodium spp. infection target a variety of pre-erythrocytic and blood stage antigens of the parasite[1]. When an endemic population demonstrates a degree of clinical or parasitological resistance, identifying an association between immunological recognition of a given antigen and resistance to malaria may indicate the antigen's potential value as a malaria vaccine candidate. Defining background responses is also useful for planning vaccine trials in endemic areas, due to the need to distinguish vaccine-induced responses from the baseline of naturally acquired responses once the vaccine is administered. Additionally, knowing this baseline and comparing immune responses post immunization with the responses obtained in malaria-naïves helps to assess whether naturally-acquired responses can be boosted by the candidate malaria vaccine.

Many studies have used immunofluorescence antibody assays (IFA) and enzyme linked immunosorbent assays (ELISA) to measure naturally acquired anti-malaria antibodies. In some cases, immunological studies have demonstrated an association between positive anti-merozoite[2] or anti-pre-erythrocytic[3] antibodies and incidence of malaria infection. IFA positivity has generally been defined by titres equal to or higher than the dilution of control sera not giving a positive immunofluorescence with the test antigen[4,5], while ELISA positivity has generally been defined as titres greater than the mean $+3 \mathrm{SD}$ of the negative control samples ("classical approach"). It has been pointed out that there are problems associated with the classical approach when negative and positive samples are not well separated and the background levels of controls are variable; in this case, a latent class model may better estimate the proportion of positive samples [6]. However, it seems best suited to estimating the proportion of positive samples rather than identifying each sample as positive or negative, which is the objective of this study, and so was not used. Because the "the classical method" yielded many positive samples due to the small SD of negative controls, a second, more stringent method was also applied, in which a sample was deemed positive if it met criteria for the first method and simultaneously showed an optical density $(\mathrm{OD}) \geq 0.5$ at a dilution of $>1 / 100$.

Defining baseline, naturally acquired $\mathrm{T}$ cell immunity is more challenging, since activities of $\mathrm{T}$ cells measured using different assays in malaria endemic areas are low, vary over time[7-9] and are HLA-restricted[9]. Earlier studies, using proliferative or cytotoxic $\mathrm{T}$ cell responses to measure T-cell immunity, identified various epitopes within CSP [10-13], MSP1 [14-19], LSA1 SSP2/TRAP CSP [20-22] and AMA1[23,24] that induced recall responses in residents of endemic areas. In general, these $\mathrm{T}$ cell responses were short lived and did not clearly correlate with natural-transmission induced immunity defined as resistance to clinical malaria. Moreover, patent infections with $P$. falciparum appeared to suppress T cell responses[25]. Subsequently, ex vivo ELISpot assays were shown to be more sensitive than CTL assays [26,27]. However, ELISpot responses were also of low magnitude [9] and relatively unstable over time [7-9]. In studies in The Gambia and Kenya [28], positive ELISpot activities ranged from $28-34 \mathrm{sfc} / \mathrm{m}$ to SSP2/TRAP, $32-60 \%$ of volunteers responded, and responses differed when measured one year apart [9]. With MSP-1, responses differed when measured three weeks apart[8]. Such studies relied on a single assay per sample, albeit often using replicate wells; so far there have been no studies reporting whether such single assays reproducibly represent $\mathrm{T}$ cell immunity and thus whether differences measured at different time points might reflect intrinsic variation in the assay as much as changing $\mathrm{T}$ cell function.

ELISpot assays are generally defined as positive when a statistically significant difference is found between test samples and medium controls using the Student $t$ test [29-31] or chi-square comparison[32], but often mean $\mathrm{sfc} / \mathrm{m}$ induced by an antigen have been low and within the range of medium-only controls[29,33].

To assess baseline immune responses as well as their reproducibility, in preparation for vaccine trials in endemic areas of West Africa, healthy adult subjects were recruited from two sites in southern Ghana, the rural community of Mampong about 35 kilometres northeast of Accra, and the urban community of Legon, a northern suburb of Accra and site of the University of Ghana. In Part A of this study, IFA was used to measure antibodies to sporozoites and blood stage parasites, and ELISA was used to measure antibodies to the candidate recombinant protein vaccine antigens CSP, SSP2/TRAP, EXP1, LSA1, MSP1 and MSP3[10-24,34]. Antibody assays were defined as positive using the two approaches described above. Ex vivo interferon-g (IFN- $\gamma$ ) ELISpot assays were also performed, using fresh PBMC stimulated with HLA-matched peptides from the candidate antigens CSP, SSP2/TRAP, EXP1, LSA1 and LSA3. In the ELISpot assays, positive activity was determined by requiring a statistically significant difference between test sample (done in quadruplicates) and medium control using Student's $t$ test, plus a 2-fold greater value than medium controls and at least a $10 \mathrm{sfc} / \mathrm{m}$ difference between test sample and medium controls.

Part B of the study was conducted two and a half years later using a different set of 12 volunteers, to assess the intrinsic reproducibility of the ELISpot assay. Cell samples were drawn from each study volunteer approximately two weeks apart and each sample was 
assayed three times on three different days to measure assay variability. Reproducibility of the assay was defined as the proportion of assays yielding either all positive or all negative results in the three replicate assays from a single sample time point while reproducibility over time was defined by comparing results from two time points.

Peptide pools spanning the full length of the test antigens CSP and AMA1 were used for stimulation in Part $B$ rather than HLA-matched peptides, as a more straightforward approach that avoided having to perform HLA typing for each volunteer. Three statistical methods using different cut-off criteria of varying stringency were used to define positive responses to see which provided optimal results; (1) Least stringent: a greater than $20 \mathrm{sfc} / \mathrm{m}$ difference between peptide stimulated samples and medium controls; (2) Medium stringent (same as Part A): a significant difference on Student's $t$ test comparing test samples and medium controls, at least twofold difference comparing test samples and medium controls, and at least a $10 \mathrm{sfc} / \mathrm{m}$ difference between test samples and medium controls; and (3) Most stringent: based on criteria established for chronically HIVinfected subjects where a positive response was defined as a minimum of $55 \mathrm{sfc} / \mathrm{m}$ and a 4-fold difference over the medium controls [35]. Volunteers who developed positive ELISpot activities to one or more peptide pools were designated as positive responders.

\section{Methods}

\section{Ethics}

This study was conducted according to a human use protocol "Quality Control of Immunological Reagents and Validation of Improvements to Immunological Assays in Support of Malaria Vaccine Trials," approved by Institutional Review Boards at the Noguchi Memorial Institute for Medical Research (NMIMR) and the Naval Medical Research Center (NMRC). NMIMR holds a United States Government Federal Wide Assurance (FWA00001824) from the Office for Human Research Protections, as does NMRC (FWA00000152). NMRC also holds a Department of the Navy Addendum to the FWA for human subject protections. The protocol was conducted in accordance with all federal regulations regarding the protection of human participants in research including The Nuremberg Code, The Belmont Report, The Helsinki Declaration (1964 and as subsequently amended), 32 CFR 219 (The Common Rule) and all regulations pertinent to the Department of Defense, the Department of the Navy, the Bureau of Medicine and Surgery of the United States Navy and internal NMRC policies for human subject protections and responsible conduct of research. All NMRC and NMIMR personnel contributing to or performing human research efforts were certified as having completed human research ethics education curricula and training under the direction of the NMRC Office of Research Administration (ORA) and Human Subjects Protections Program (HSPP).

\section{Study site}

Mampong town with a total population of approximately 8000 is located in the Akuapem North district in the Eastern Region of Ghana about $35 \mathrm{~km}$ northeast of Accra. It lies on the Akuapem-Togo mountains range, with an elevation ranging between $381 \mathrm{~m}$ and $487.7 \mathrm{~m}$ above sea level. The spoken language in Mampong is Twi and the major occupation is farming, although a substantial proportion of individuals work in the district offices, hospital or schools. Health services are provided by the Ghana Health Service through the District Health Management Team, the Tetteh Quarshie Memorial Hospital, the Centre for Scientific Research into Plant Medicine, and also by some private clinics and traditional healers. The climate is cooler than in Accra and the area receives on average about $2000 \mathrm{~mm}$ of rainfall a year. Malaria transmission occurs throughout the year, but most malaria admissions at the district hospital occur during the months of April to November. Among 21 residents of Mampong sampled for a baseline study of immune responses in September 2002, a third (7/21) had peripheral $P$. falciparum parasitemia detected by thick film examination. Malaria is the leading cause of pediatric admissions and outpatient attendance at the district hospital.

The Legon area is approximately $10 \mathrm{~km}$ north from the centre of the capital city, Accra. It is well settled and home to the University of Ghana that has a large student population of over 20,000. Accra and its environs lie on a relatively flat coastal plain with the highest elevation being less than $100 \mathrm{~m}$ above sea level. Rainfall is less intense and less frequent than in Mampong. The average annual rainfall is below $1000 \mathrm{~mm}$ with more than half falling between April and June. Malaria transmission follows the pattern of rainfall and most malaria admissions to the health facilities occur between May and August. Malaria transmission in this urbanized and settled area occurs mainly along the peri-urban fringes that have suitable breeding sites for the anopheles vector in uncompleted buildings and excavated areas. In a survey of 20 individuals for a baseline study of immune responses, none were positive by thick blood film examination, and in a recent (May 2010) screen of 111 volunteers for another study only one was positive by thick film examination.

The study is based on the rationale that transmission and therefore immunity differs between Mampong and Legon. Part A of this study was conducted on blood samples drawn in April 2005 and Part B on samples drawn in October 2007. 


\section{Participants}

Eligibility criteria for the study were the following: age 18-55 years; males or females who were not pregnant or nursing; normal screening medical history and physical examination; hemoglobin >10 g/dL; absence of known immunodeficiency (> $400 \mathrm{CD} 4+\mathrm{T}$ cells $/ \mu \mathrm{L})$; and negative hepatitis $\mathrm{B}$ and $\mathrm{C}$ serology.

\section{Sample collection}

Blood was obtained by venipuncture and transferred into heparinized flasks using aseptic techniques. All blood samples were transported in cool boxes to the Department of Immunology of the NMIMR for analysis. Peripheral blood mononuclear cells (PBMCs) were separated from the blood samples by density centrifugation, washed and counted. Plasma obtained from the same separation procedure was distributed into aliquots and stored at $-80^{\circ} \mathrm{C}$ for assessment of antibody levels. Blood smears were stained with Giemsa and examined for the presence of Plasmodium species using light microscopy.

\section{Control blood samples}

Sera from malaria-naïve adults from Denmark and the USA were also used in ELISA and IFA assays.

\section{HLA typing}

For each participant in Part A, low-moderate resolution HLA typing for HLA-A, HLA-B, and HLA-DR was conducted using the ABDR SSP Unitray system (Pel-Freez, Brown Deer, WI) according to the manufacturer's instructions.

\section{Synthetic peptides and peptide pools}

For Part A, thirty-two short peptides (8-11 amino acids) with known restriction by HLA-A or HLA-B alleles and 25 long peptides (15-34 amino acids) that were DR epitopes from CSP, SSP2/TRAP, EXP1, LSA1 and LSA3 $[36,37]$ were synthesized commercially (Chiron Technologies, Clayton, Victoria, Australia) and were used to assess IFN- $\gamma$ ELISpot responses. Positive control peptides for CD8 + T cell-mediated responses consisted of HLA-A2.1 or -A3 restricted peptides derived from CMV or influenza virus. Purified protein derivative (PPD) (Statens Serum Institute, Copenhagen) was used as a positive control for CD4+ T cell responses.

For Part B, ELISpot assays used peptide pools of 15 amino acid (aa) synthetic peptides overlapping by 11 aa (Chiron Technologies, Clayton, Victoria, Australia) covering full length CSP and AMA1(>80\% purity). These were combined into nine pools for CSP (Cp1Cp9) containing 3-12 peptides per pool and 12 pools for AMA1 (Ap1-Ap12) containing 10-12 peptides per pool [31].

\section{Enzyme-linked immunosorbent assay (ELISA)}

The $P$. falciparum recombinant proteins used in the ELISA assays; CSP, SSP2/TRAP, LSA1, EXP1, MSP1, MSP3, EBA175 have been previously described [38-43]. Stock solutions of $P$. falciparum recombinant proteins were diluted in phosphate buffered saline, $\mathrm{pH} 7.2$, to the optimal concentration of each antigen (0.1-4 $\mu \mathrm{g} / \mathrm{ml})$. ELISA was performed as previously described[44] using quadruplicates of serum diluted two-fold from 1/50 to 1/5120. The endpoint titre of antibodies was defined as the calculated serum dilution yielding an optical density of 0.5 in the assay.

\section{Analysis of positive end points}

To determine whether the ELISA activity was defined as positive, two methods were used. The first was an OD that was above the mean of control negative donors (Danish volunteers with no previous exposure to malaria) + 3 standard deviations (SD). Since these differences were often small, a second quantitative method was applied: a positive activity was defined as an $\mathrm{OD} \geq$ 0.5 at a dilution of $>1 / 100$ and greater activity than control sera +3 SD. The numbers of total positive ELISA activities per volunteer was determined in urban and rural volunteers using both methods.

\section{Immunofluorescent Antibody Assay (IFA)}

P. falciparum (strain 3D7) sporozoite-specific antibodies were assayed by immunofluorescent staining of air-dried $P$. falciparum sporozoites, and P. falciparum (strain 3D7)-infected erythrocytes cultured in vitro, as described previously[45].

\section{Ex vivo IFN- $\gamma$ ELISpot Assays Part $A$}

ELISpot assays were performed as previously described (42) using freshly isolated PBMC in quadruplicate using 400,000 cells/well. Each volunteer's PBMC were tested against 8-11-mer HLA Class I binding peptides, or long 15-34-mer HLA Class II binding peptides that matched the volunteer's HLA type $(10 \mu \mathrm{g} / \mathrm{mL})$. To reduce the number of ELISpot assays some peptides were combined into mixtures: long peptides: CSP D44 + D49, D46 + D47; SSP2/TRAP, D51-D59; LSA1 D64-D68; LSA3, D70 + D72; EXP1 D60 + D61 (6 peptide mixtures + 3 single peptides $=9$ stimulants); short peptides: CSP D2 + D3, D4 + D5, SSP2/TRAP D12-D14, LSA1 D23-D26, LSA3 D31-35, EXP1 D18-D21. (6 peptide mixtures + 12 single peptides $=18$ stimulants). $\mathrm{PPD}$ was used as a positive control for PBMC biomarkers[46], and the negative control was medium only as used by others (for example [47]). CEF peptides (which include epitopes from cytomegalovirus, Epstein-Barr virus and influenza virus recognized by $\mathrm{CD} 8+\mathrm{T}$ cells) were included in assays as positive controls. 


\section{Statistical analysis}

To identify positive ELISpot activities, differences between means of peptide-stimulated and non-stimulated (medium only controls) were compared as used in current NMRC vaccine trials based on previously described methods[48]. The assay was considered positive if there was (1) a statistically significant difference between the number of spot forming cells in triplicate or quadruplicate test wells and triplicate or quadruplicate control wells (Student's two tailed $t$-test), plus (2) at least a doubling of spot forming cells in test wells relative to control wells, and (3) a difference of at least 10 spots between test and control wells (modified from $\geq$ five spots as previously described[48]. The average of medium controls was subtracted from test samples and reported as adjusted sfc/m PBMC. Any well that contributed more than $50 \%$ of the standard deviation of the quadruplicate and which was either three-fold greater or lower than the mean of the remaining cells were discarded as an outlier. The volunteer was designated as a responder at a single time point if his/her PBMC tested positive against at least one of the peptides for a given antigen.

\section{Part B}

ELISpot assays used pools (at $10 \mu \mathrm{g} / \mathrm{mL}$ ) of synthetic 15-mer peptides spanning full length CSP or AMA-1 based on the premise that at least one peptide within a pool should have the correct sequence recognized by any HLA within the study population. Twelve volunteers were each sampled up to four times; samples for CSP were drawn on day 0 and day 14, and samples for AMA1 were drawn on day 9 and day 21 . Thus the two sample time-points selected to control short term reproducibility were approximately two weeks apart for each antigen. Frozen PBMC aliquots from each sample were then tested in three separate ELISpot assays (1,2 and 3) each performed on different days, and each sample from each assay was performed in triplicate. Each sample was tested with either 9 CSP peptides/peptide pools (Cp1 Cp9) or 12 AMA1 peptides/peptide pools (Ap1 - Ap12) at $10 \mu \mathrm{g} / \mathrm{mL}$. Positive controls were ConA (mitogen for cell viability) and CEF (a pool of peptides from cytomegalovirus, Epstein Barr virus and influenza virus that specifically stimulate CD8+ T cells).

\section{Statistical analysis}

To distinguish specific ELISpot responses, ELISpot activities using CSP or AMA1 peptide pools were compared with medium only controls and specific activity was determined using three methods of increasing stringency. Method 1: average of peptide pool stimulated activity minus that of the average of medium controls, with an arbitrary cut off of $20 \mathrm{sfc} / \mathrm{m}$. Method 2: that used in Part A. Method 3: the cut off described for HIV gag protein[8], namely a median of $>55 \mathrm{sfc} / \mathrm{m}$ and at least four-fold greater than the median of medium-only controls. As in Part A, a volunteer was designated as a responder at a given time point if his/her PBMC tested positive against at least one of the peptide pools for a given antigen.

\section{Results}

\section{Participant flow}

In Part A, 35 healthy adult volunteers recruited in Legon $(n=14)$ and in Mampong $(n=21)$ met the eligibility criteria and passed clinical and laboratory screening and were HLA-typed. Sera were tested in IFA and ELISA. PBMC were collected from 30 of these volunteers (Legon $n=13$, Mampong $n=17$ ) and fresh PBMC were stimulated with Class I and Class II peptides in ELISpot assays. Volunteer identification numbers, parasitaemia status and the tests performed are shown in Additional File 1 for the two communities.

In Part B, 12 new urban volunteers donated PBMC on four different days. The PBMC were frozen and tested in ELISpot assays using pools of overlapping peptides spanning the length of CSP and AMA1. Of these 12, seven were included in the analysis of reproducibility. Five were excluded because sampling was incomplete or else there were insufficient PBMCs to complete the analysis. Two of the seven volunteers (v1001 and v1041) had blood drawn only on two of the four sample days but were included for the antigen for which the sample set was complete.

\section{Antibody responses \\ IFA titres of urban and rural volunteers}

The geometric mean anti-sporozoite IFA titres were 860 and 580 for residents of Accra and Mampong, respectively (Figure 1). The difference in titres between the two sites was not significant $(\mathrm{P}=0.44$, two tailed $\mathrm{t}$-test on log transformed data). Geometric mean anti-infected erythrocyte titres were 22,000 and 55,000 in samples from Accra and Mampong, respectively, which likewise were not significantly different although there was a trend toward higher responses in the rural community ( $\mathrm{P}=0.081$, two tailed $\mathrm{t}$-test, $\log$ transformed). Sera from malaria-naive North American subjects did not react in IFA at dilutions greater than 1:10 (sporozoites) or 1:20 (infected erythrocytes).

\section{ELISA titres of urban and rural volunteers}

Activity was defined as the calculated serum dilution yielding an optical density of 0.5 in the assay[49]. The ELISA titres of 14 urban and 21 rural volunteers to seven $P$. falciparum candidate vaccine antigens are shown in Figure 2. While there are limitations to comparing titres to different antigens measured in different ELISA assays, group mean titres against the sporozoite antigens CSP and SSP2/TRAP were approximately ten- 


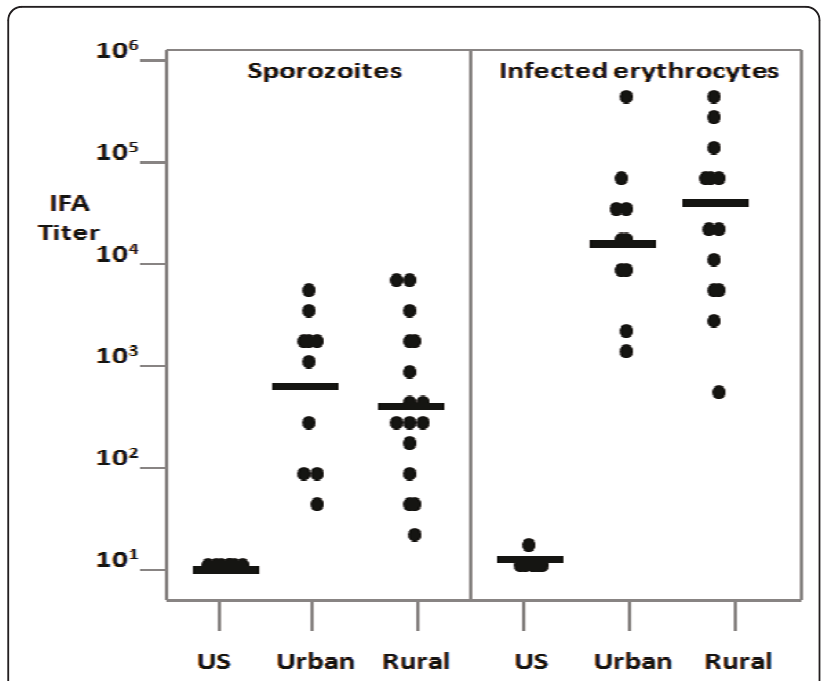

Figure 1 IFA titers of sera from volunteers in Accra or Mampong compared with naïve controls from the US. Horizontal bars represent geomean titers and filled circles represent individual titers

fold lower than those against the major blood stage antigens MSP1, MSP3, and EBA175, consistent with the lower IFA titres against sporozoites compared to infected erythrocytes. There was a trend for higher titres against all antigens in the Mampong subjects compared

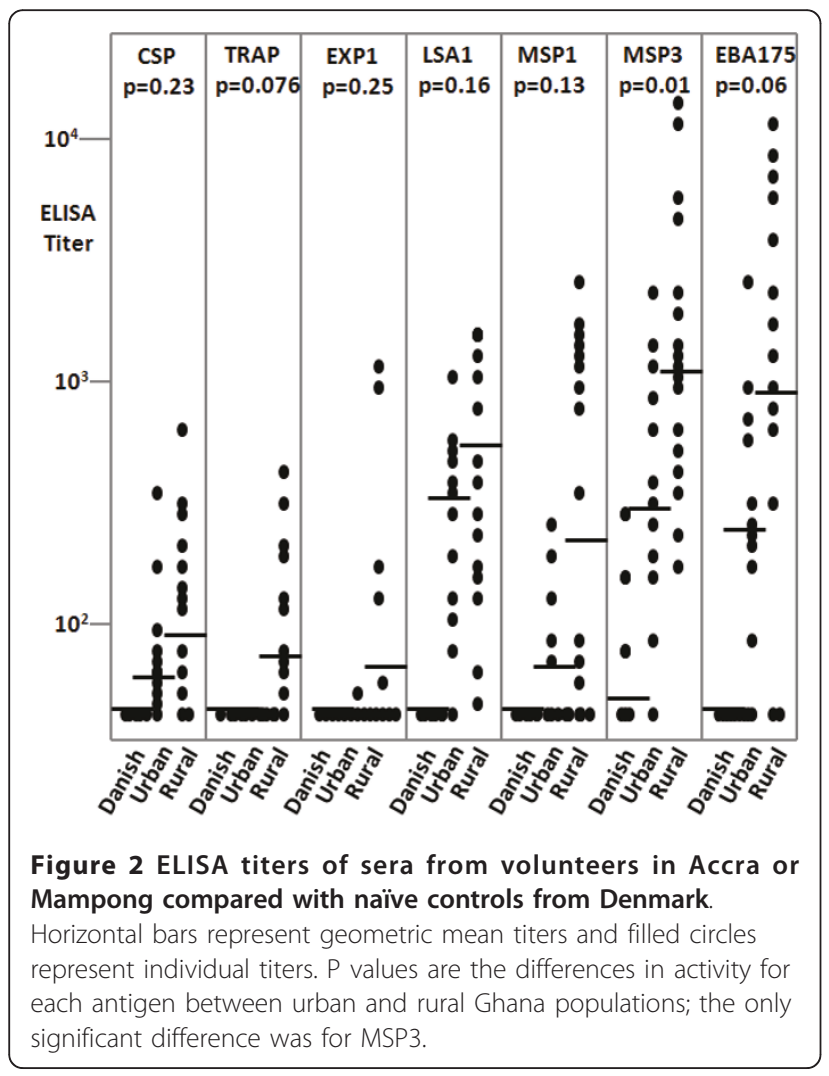

with those from Legon, although the difference was statistically significant only with MSP3.

The several antibody responses measured in each individual were moderately well correlated. In pair-wise correlations, log transformed ELISA titres to each of the four primarily erythrocytic stage antigens (MSP1, MSP3, EBA175, EXP-1) were correlated with each of the others $(\mathrm{R}=0.5-0.7, \mathrm{p}=0.003-0.0001)$ and to the IFA titres against infected erythrocytes $(\mathrm{R}=0.4-0.6, \mathrm{p}=0.03$ $0.0001)$. Similarly, ELISA titres against the three pre-erythrocytic stage antigens (CSP, SSP2/TRAP, LSA1) were significantly correlated with each other and with the sporozoite IFA titres $(\mathrm{R}=0.5-0.6, \mathrm{p}=0.007-0.0005)$, except that titres against SSP2/TRAP were not significantly correlated either with titres to PfCSP or to sporozoites. Six of the volunteers from Mampong had $P$. falciparum parasitaemia on the day samples were collected. There was no significant difference in antibody titres in all ELISA assays between subjects with or without parasitaemia $(\mathrm{p}=0.41$ Mann Whitney $\mathrm{U}$ test twotailed).

\section{Definition and frequency of positive ELISA responses in urban and rural volunteers}

Method 1 The mean ELISA activities from all the urban or rural volunteers were greater compared with the mean +3 SD of the OD of control sera for at least one antigen (Table 1 and Additional File 2). Four erythrocytic stage antigens (EXP1, MSP1, MSP3 and EBA175), and two pre-erythrocytic antigens SSP2/TRAP and LSA1 were frequently positive. A major exception was CSP where only $2 / 14(14 \%)$ of urban and $11 / 21$ (52\%) of rural volunteers had positive responses. Urban volunteers were positive with fewer numbers of antigens than rural volunteers (4.9 and 5.9 antigens/volunteer respectively) and this difference was significant ( $p=0.026$, Mann-Whitney U test, 2 tailed).

Method 2 When the more stringent second method was applied (Table 1 and Additional File 3), the numbers of urban and rural volunteers positive with CSP, SSP2/ TRAP, EXP1 and EBA175 declined compared to the outcomes using the first method. However, all volunteers were positive with at least one malaria protein. The frequencies of positive assays with LSA1 and MSP3 remained similar, but slightly declined for MSP1 and declined more greatly for EXP1 and SSP2/TRAP. The greatest decline was with EBA175 and CSP; CSP was only positive with rural volunteers. The numbers of antigens recognized by urban and rural volunteers were 3.4 and 3.9 antigens/volunteer respectively and this difference was not significant $(p=0.5)$, in contrast to using method 1 . The different outcome likely relates to the lower frequencies obtained with method 2 compared with method 1 for urban and rural volunteers $(\mathrm{p}=0.02$, $\mathrm{p}=0.001$ respectively), and this was largely attributable 
Table 1 The frequency of positive ELISA activities conducted in urban and rural volunteers with 7 recombinant proteins representing some candidate vaccine antigens

\begin{tabular}{|c|c|c|c|c|c|c|c|c|c|c|c|}
\hline Method & & & & & & tigens tes & & & & & \\
\hline \multirow[t]{4}{*}{1} & Site & No. vol & CSP & TRAP & EXP1 & LSA1 & MSP1 & MSP3 & EBA & Total & Tot/v \\
\hline & Urban & 14 & $2^{*}(14 \%)$ & $10(71 \%)$ & 11 (79\%) & $12(86 \%)$ & 11 (79\%) & $14(100 \%)$ & $8(57 \%)$ & 69 & 4.9 \\
\hline & Rural & 21 & $11(52 \%)$ & $21(100 \%)$ & 19 (90\%) & $20(95 \%)$ & 17 (81\%) & $20(95 \%)$ & $16(90 \%)$ & 124 & 5.9 \\
\hline & Total & 35 & $13(37 \%)$ & 31 (89\%) & 30 (86\%) & 32 (91\%) & $28(80 \%)$ & 34 (97\%) & 24 (86\%) & 192 & 5.5 \\
\hline \multirow[t]{3}{*}{2} & Urban & 14 & $0(0 \%)$ & $4(29 \%)$ & $5(36 \%)$ & $12(86 \%)$ & $10(71 \%)$ & $14(100 \%)$ & $2(14 \%)$ & 47 & 3.4 \\
\hline & Rural & 21 & $5(24 \%)$ & $10(48 \%)$ & 10 (48\%) & 19 (90\%) & $14(67 \%)$ & 19 (90\%) & $5(24 \%)$ & 82 & 3.9 \\
\hline & Total & 35 & $5(14 \%)$ & $14(40 \%)$ & 15 (43\%) & 31 (89\%) & $24(69 \%)$ & $33(94 \%)$ & $7(20 \%)$ & 129 & 3.7 \\
\hline
\end{tabular}

Positive ELISA activities were defined using method 1 (OD that was above the mean of control negative donors (Danish volunteers with no previous exposure to malaria) $+3 \mathrm{SD}$ ) or method 2 (OD $\geq 0.5$ at a dilution of $>1 / 100$ and greater activity than control sera +3 SD). The Table shows the numbers of urban and rural volunteers that were positive with each antigen. The total numbers of antigens positive with urban and rural volunteers, and the frequency of positive antigens/ volunteer (Tot/v) are shown in the two right columns. ${ }^{*}$ Number of volunteers positive.

to differences with CSP, SSP2/TRAP, EXP1 and EBA175.

Six volunteers had malaria parasitaemia at the time the samples were taken but they appeared to recognize the same numbers of proteins as non-infected volunteers using method 1 and method 2 (Additional Files 2 and 3).

\section{Ex vivo IFN- $\gamma$ ELISpot responses}

Part $A$

Peptides used in Part $A$ Six mixtures and three single peptides (nine stimulants) of long DR-restricted and six mixtures and 12 single peptides of HLA A or Brestricted short peptides (18 stimulants) were used, and were numbered 1-27 (see Additional File 4 for sequences). Since this assay was based on matching the HLA of each volunteer with matched HLA A- or B- or DR peptides, not every volunteer was tested with every peptide. The combinations that were tested are shown in Additional File 5.

DR peptides: All volunteers were tested with five of the DR-binding peptides (all of these being mixtures) except one volunteer (v1340) who was not tested with LSA3. The remaining four DR stimulants (one mixture and three single peptides) were matched to varying numbers of volunteers based on predicted HLA A or B epitopes within their sequences. This resulted in 169 assays, 76 assays with 13 urban volunteers and 93 assays with 17 rural volunteers (Table 2, Additional File 5)

HLA-A and B-restricted peptides: HLA matching peptides were available for 15 volunteers for CSP, 13 volunteers for SSP2/TRAP and LSA1, and 12 volunteers for EXP1 and LSA3, representing 17 of the 30 volunteers. These included matches for HLA-A01, -A02, -A02.1, -A03, -B07, -B35 and -B53. HLA matching for the A and $B$ loci was based on HLA type, not supertype. This study did not have peptides matching the other HLA alleles identified in the study subjects. This resulted in 96 assays; 52 assays with 8 urban volunteers and 44 assays with 9 rural volunteers (Table 2, Additional File 5).

Frequency of positive assays When all assays were analysed (Table 2), long DR-specific peptides elicited fewer responses in urban volunteers (11/76 assays, 14.5\%) than rural volunteers (22/93 assays, 23.7\%). Positive responses to DR-specific peptides were approximately twice as frequent as responses to short HLA class I peptides in both populations (urban $3 / 52$ assays $5.8 \%$, rural $5 / 44$ assays $11.4 \%$,) (Table 2). In total, there were 14/128 (10.9\%) positive assays with urban volunteers and $27 /$ 137 (19.7\%) positive assays with rural volunteers, suggesting that ELISpot responses to individual peptides or peptide pools were more frequent in rural than urban volunteers, with the caveat that a restricted number of

Table 2 Frequency of positive ELISpot assays conducted in urban and rural populations using long (LP) and short (SP) peptides

\begin{tabular}{ccccccc}
\hline & \multicolumn{2}{c}{ No. assays } & Total & \multicolumn{2}{c}{ No. positive assays/all assays } & Total \\
\hline Pop. & LP & SP & LP+SP & LP & SP & LP+SP \\
\hline Urban $(\mathbf{n}=\mathbf{1 3})$ & 76 & 52 & 128 & $11 / 76(14.5 \%)$ & $3 / 52(5.8 \%)$ & $14 / 128(10.9 \%)$ \\
\hline Rural $(\mathbf{n}=\mathbf{1 7})$ & 93 & 44 & 137 & $22 / 93(23.7 \%)$ & $5 / 44(11.4 \%)$ & $27 / 137(19.7 \%)$ \\
\hline Total & 169 & 96 & 265 & $33 / 169(19.5 \%)$ & $8 / 96(8.3 \%)$ & $41 / 265(15.5 \%)$ \\
\hline
\end{tabular}

Six mixtures and 3 single peptides (9 stimulants) of long (DR-binding) or 6 mixtures and 12 single of short (HLA A or B-restricted) peptides (18 stimulants) were tested with HLA-matched urban and rural volunteers. The number of assays that were performed and the number of assays that were positive are shown and expressed as per cent of total assays. The sequences of the peptides, and how they were combined, are shown in Additional File 4. 
HLA types were tested. The volunteer-peptide combinations are shown in Additional File 5.

Frequency of positive volunteers Table 3 shows the numbers of urban and rural volunteers responding to at least one long or one short peptide. While urban volunteers had a slightly lower frequency of positive responders than rural volunteers to long peptides (urban: 6/13 volunteers, $46.2 \%$; rural: $9 / 17$ volunteers, $52.9 \%)$ and to short peptides (2/8 urban volunteers, $25 \%$; $3 / 9$ rural volunteers, 33.3\%), taken together, urban and rural responders to both long and short peptides were similar (urban 8/13 volunteers, $61.5 \%$ of volunteers; rural 9/17 volunteers, $52.9 \%$ of volunteers). Therefore, while rural volunteers recognized more peptides than urban volunteers (Table 2), there was no difference in the frequency of volunteers who were positive to one or more peptides (Table 3).

Magnitude of ELISpot responses to long DR-restricted peptides from each antigen The volunteers recognized the 6 mixtures of DR-restricted long peptides but none of the single peptides (Table 4). One mixture (number 22 ) and the 3 single peptides were only tested with 8 and 6 HLA A and B matched volunteers respectively, and it is possible that testing more volunteers with these peptides may have revealed additional positive outcomes. Positive responses were obtained with peptides from all five malaria proteins tested: CSP, SSP2/TRAP, LSA1, LSA3 and EXP1. ELISpot responses ranged from $70-430 \mathrm{sfc} / \mathrm{m}$, and were similar for urban and rural volunteers $(\mathrm{p}=0.44$ Mann Whitney $\mathrm{U}$ test two-tailed). LSA1 was most frequently recognized (11/30 volunteers, $37 \%$ ), followed by SSP2/TRAP (8 volunteers, 27\%), EXP1 (6 volunteers, 20\%), LSA3 (4 volunteers, 14\%) and CSP (3 volunteers, 10\%).

Magnitude of ELISpot responses to short HLA A- and $B$-restricted peptides from each antigen Only a few positive responses to short HLA A- and B-restricted peptides were identified (Table 5) and this may reflect the more limited numbers of volunteers and HLAmatched peptides that were tested. 2/8 (25\%) urban volunteers (both HLA-A 02) recognized three short Class I-restricted peptide mixtures from CSP, SSP2/

Table 3 Frequency of volunteers with positive ELISpot responses conducted in $\mathbf{3 0}$ volunteers from urban and rural populations

\begin{tabular}{|c|c|c|c|}
\hline \multirow[b]{2}{*}{ Pop. } & \multicolumn{3}{|c|}{ No. positive volunteers } \\
\hline & No. LP positive & No. SP positive & Pos. All peptides \\
\hline Urban $(n=13)$ & $6 / 13(46.2 \%)$ & $2 / 8(25.0 \%)$ & $8 / 13(61.5 \%)$ \\
\hline Rural (n = 17) & 9/17 (52.9\%) & $3 / 9(33.3 \%)$ & 9/17 (52.9\%) \\
\hline
\end{tabular}

TRAP and LSA3. Three of nine (33\%) rural volunteers (HLA A03 and HLA B53) recognized five short Class-I restricted peptides (all single peptides) from CSP, SSP2/ TRAP, LSA1 and LSA3 (Table 5). Activities with short peptides ranged from 73 to $258 \mathrm{sfc} / \mathrm{m}$. Responses of urban and rural volunteers to short peptides were similar ( $p=0.65$ Mann Whitney $\mathrm{U}$ test two-tailed). Responses of urban and rural volunteers to short and long peptides were also similar in both groups of volunteers $(p=0.58$ and $p=0.39$ for urban and rural, respectively, Mann Whitney $U$ test two-tailed). The sequences of all positive long and short peptides are shown in Additional File 4. In total, 14/32 (43.8\%) short peptides and 22/25 (88\%) long peptides were active in these ELISpot assays, either as single peptides or as part of mixtures of peptides (Additional Files 4 and 5).

Effect of parasitaemia on ELISpot activity Six individuals in the rural population had malaria parasites when venous blood samples were drawn, and three (50\%) were positive with long DR peptides (Table 4), but none

Table 4 Individual urban and rural volunteers' fresh ELISpot activity with DR-matched long Class II-restricted peptides

\begin{tabular}{|c|c|c|c|c|c|c|c|}
\hline & & & & SSP2 & LSA1 & LSA3 & EXP1 \\
\hline Site & Vol. & $\begin{array}{l}\text { D44, } \\
\text { D49 }\end{array}$ & $\begin{array}{l}\text { D46, } \\
\text { D47 }\end{array}$ & $\begin{array}{l}\text { D51- } \\
\text { D59 }\end{array}$ & $\begin{array}{l}\text { D64- } \\
\text { D68 }\end{array}$ & $\begin{array}{l}\text { D70, } \\
\text { D72 }\end{array}$ & $\begin{array}{l}\text { D60, } \\
\text { D61 }\end{array}$ \\
\hline Urban & 113 & 295 & 145 & 283 & 233 & 208 & \\
\hline & 614 & & & & 103 & & \\
\hline & 815 & & & & 110 & & \\
\hline & 816 & & & & 83 & & \\
\hline & 917 & & & & 250 & & 70 \\
\hline & $\begin{array}{c}1123 \\
+ \\
\end{array}$ & & & & 365 & & \\
\hline Rural & 1324 & & & 90 & 88 & & 245 \\
\hline & 1326 & 85 & & 140 & 100 & 98 & 113 \\
\hline & $\begin{array}{c}1330 \\
+\end{array}$ & & & & 200 & & 103 \\
\hline & 1331 & & & 150 & 193 & & 318 \\
\hline & 1332 & & & 243 & & 343 & \\
\hline & 1341 & 83 & & 100 & & 210 & 168 \\
\hline & 1342 & & & 430 & & & \\
\hline & 1345 & & & 95 & & & \\
\hline & $\begin{array}{c}1351 \\
+\end{array}$ & & & & 70 & & \\
\hline
\end{tabular}

All 30 volunteers were tested with DR peptides from CSP (four), SSP2/TRAP (nine), EXP1 (two), LSA1 (five) and LSA3 (two), except for volunteer 1340, who was not tested against LSA3. Six of 13 urban and nine of 17 rural volunteers had ELISpot activities that were identified as positive and are listed in this table. Each number represents the mean of quadruplicate wells in a single assay expressed as $\mathrm{sfc} / \mathrm{m}$, with medium controls subtracted. A "+" next to the volunteer identification number in the second column indicates patent parasitemia at the time the sample was taken [see Methods]. The peptides that were not recognized by any of the volunteers as well as the volunteers not having any positive responses are shown in Additional File 5. 
Table 5 Individual urban and rural volunteers' ELISpot activity with HLA A or HLA B-matched short Class Irestricted peptides

\begin{tabular}{|c|c|c|c|c|c|c|c|c|}
\hline & & CSP & & SSP2/TP & AP & LSA1 & LSA3 & \\
\hline Site & Vol. & D4, D5 & D6 & D12-D14 & D15 & D29 & D31-D35 & D37 \\
\hline \multirow[t]{2}{*}{ Urban } & 506 & 173 & & & & NT & 180 & \\
\hline & 510 & & & 73 & & NT & & \\
\hline \multirow[t]{3}{*}{ Rural } & 1326 & & 95 & & 88 & & NT & NT \\
\hline & 1331 & & & & & & & 93 \\
\hline & 1341 & NT & NT & NT & NT & 258 & & 208 \\
\hline
\end{tabular}

HLA-matches were defined for an HLA A or B allele. Two of 13 urban (506 and 510) and three of 17 rural $(1326,1331$ and 1341) volunteers had positive ELISpot responses with HLA-matched short Class I-restricted peptides. Each number represents the mean of quadruplicate wells in a single assay with medium subtracted. No volunteer was infected with malaria. None of the twelve volunteers tested with EXP1 peptides were positive. NT = Not Tested:

were positive with class I peptides, suggesting that the frequency of ELISpot responses to class I peptides may be influenced by circulating parasites.

Comparison of ELISA and ELISpot activities When ELISA (Additional Files 2 and 3) using method 1 and ELISpot data (Tables 4 and 5) were examined, almost all urban and rural volunteers with positive ELISpot activities were also positive with the same antigen in ELISA, except v506 and v816 who were negative in ELISA and positive in ELISpot (with CSP D4, D5; D64-68 respectively). This may only reflect the high frequency of positive volunteers identified using method 1. However, when the more stringent method 2 analysis of positive ELISA activities was used (Additional File 3) the lower numbers of positive assays with CSP, SSP2 and EBA175 reduced this concordance, although 10/11 positive ELISpot assays with LSA-1 remained positive in ELISA.

Part $B$

Volunteers and sample schedules The objective of Part $\mathrm{B}$ was to collect PBMC at two time points and to perform ELISpot assays of cells from each of the two time points on three separate days. Twelve volunteers were initially enrolled, but only seven volunteers were used for this analysis as these seven completed blood draws when scheduled and sufficient blood was obtained to conduct nearly all the planned assays for one or both antigens. There were five with complete samples for both antigens, one with complete samples for CSP only (totalling six for CSP) and one with complete samples for AMA1 only (totalling six for AMA1). The sample availability is shown in Table 6.

PBMC were collected at days 0, 9, 14 and 21 and frozen. Assays were performed on frozen samples after all samples had been collected. Samples from day 0 and day 14 were tested in ELISpot assays with CSP peptide pools, and samples from days 9 and 21 were tested with AMA1 peptide pools. Three assays, labeled assays 1, 2 and 3 , were performed on three separate days for each time-point, starting in each case with freshly thawed PBMCs. Thus with six volunteers for CSP (v1024, v1036, v1039, v1041, v1054 and v1056), 36 assays performed with 9 CSP peptide pools for a total of 324 individual assays; and with six volunteers for AMA1 (v1024, v1036, v1039, v1054, v1056 and v1001), 35 assays were performed with 12 peptide pools (v1036 was only tested in two assays at the day 9 time point due to shortage of PBMC) for a total of 420 individual assays. In addition there were 71 medium controls assayed for the seven volunteers.

Variability in medium controls The first step was to determine the variation in ELISpot responses in control assays when PBMC's were stimulated with medium alone to establish a baseline against which positive ELISpot activities could be statistically calculated. The values of the medium only controls were examined for each of the 12 volunteers, for CSP and for AMA1, at the two time-points each with three assays (100 control

Table 6 Part B assay schedule

\begin{tabular}{|c|c|c|c|c|c|c|c|c|c|c|c|c|c|}
\hline \multirow[b]{2}{*}{ Day } & \multicolumn{3}{|c|}{ CSP SAMPLE 1} & \multicolumn{3}{|c|}{ AMA SAMPLE 1} & \multicolumn{3}{|c|}{ CSP SAMPLE 2} & \multicolumn{3}{|c|}{ AMA SAMPLE 2} & \\
\hline & 0 & 0 & 0 & 9 & 9 & 9 & 14 & 14 & 14 & 21 & 21 & 21 & \\
\hline Assay & 1 & 2 & 3 & 1 & 2 & 3 & 1 & 2 & 3 & 1 & 2 & 3 & TOTAL \\
\hline 1001 & & & & $x$ & $x$ & $x$ & & & & $X$ & $x$ & $x$ & 6 \\
\hline 1024 & $x$ & $x$ & $x$ & $x$ & $x$ & $x$ & $x$ & $x$ & $x$ & $x$ & $x$ & $X$ & 12 \\
\hline 1036 & $x$ & $x$ & $x$ & $x$ & & $x$ & $x$ & $x$ & $X$ & $x$ & $x$ & $X$ & 11 \\
\hline 1039 & $x$ & $x$ & $X$ & $x$ & $x$ & $x$ & $x$ & $X$ & $X$ & $X$ & $x$ & $X$ & 12 \\
\hline 1041 & $x$ & $x$ & $X$ & & & & $X$ & $X$ & $X$ & & & & 6 \\
\hline 1054 & $x$ & $x$ & $x$ & $x$ & $x$ & $x$ & $X$ & $X$ & $X$ & $x$ & $x$ & $X$ & 12 \\
\hline 1056 & $x$ & $x$ & $X$ & $x$ & $x$ & $x$ & $x$ & $x$ & $x$ & $x$ & $x$ & $x$ & 12 \\
\hline TOTAL & 6 & 6 & 6 & 6 & 5 & 6 & 6 & 6 & 6 & 6 & 6 & 6 & 71 \\
\hline
\end{tabular}

Each volunteer was sampled at different time points (for CSP day 0 and day 14; AMA1 day 9 and day 21). Frozen PBMC from each time point were tested in ELISpot assays with CSP or AMA peptide pools in three assays 1, 2 and 3 on different days as indicated. Assays used for analysis are boxed. $\mathrm{X}$ indicates where that volunteer was tested with CSP or AMA1 pools. The seven volunteers in the table were analysed for ELISpot reproducibility at each of the two time points (Supplementary Tables 1, 2 and 3). Totals refer to the numbers of assays used in this analysis. An additional five volunteers enrolled in the study and tested at some time points were excluded from this table and from the consistency analysis because data sets were not sufficiently complete. 
assays in total, given that not all volunteers were sampled at each time point). The frequency distribution of the medium controls is shown in Figure 3. When examined by antigen, they were nearly identical (Figure 3 ), with most values between $0-15 \mathrm{sfc} / \mathrm{m}$. This indicated a high degree of similarity regarding how the assays performed on different days, and therefore that assay results for different antigens or from different days could appropriately be compared.

\section{Reproducibility of assays}

When ELISpot activities of all peptide pools were analysed, $138 / 324$ (42.6\%) of CSP assays and 236/420 (56.2\%) of AMA1 assays were greater than medium controls (Table 7). The remaining peptide-pool activities were similar to medium controls, and could be considered as natural variability or "noise" of the ELISpot assay. The next step was to differentiate which activities were significantly different from medium controls and three sets of criteria were applied (See Methods).

\section{Method 1}

The simplest and least stringent method was to subtract the average of medium control activity from the average of antigen-stimulated activity and use a net difference of $20 \mathrm{sfc} / \mathrm{m}$ as the arbitrary cut-off [50]. The results are summarized in Table 7 and Figure 4 and details are provided in Additional File 6.

\section{Positive volunteers}

Thirty/324 (9.3\%) assays with CSP and 94/420 (22.4\%) assays with AMA1 pools were positive at this cut off (Table 7, details in Additional File 6). When all CSP positives were combined, v1054 was consistently positive (positive in all three assays) at both time-points, and

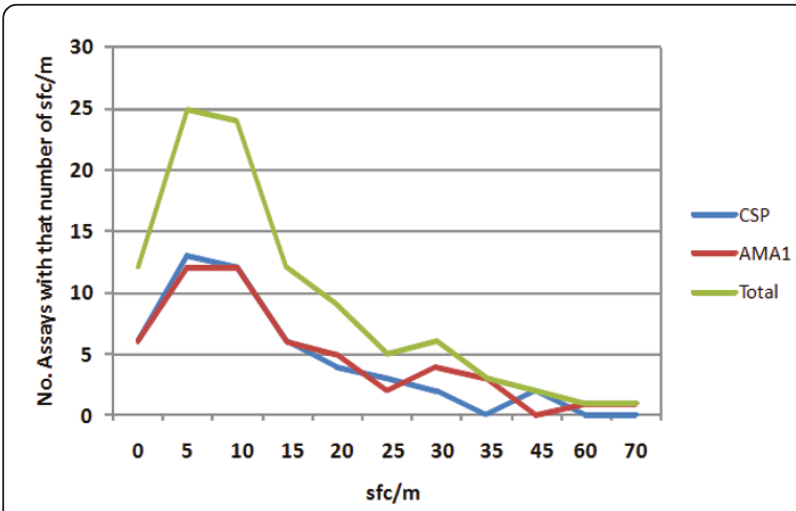

Figure 3 The frequency distribution of the medium controls ( $\mathrm{sfc} / \mathrm{m}$ PBMC) for all the CSP and AMA1 assays. The numbers of medium controls from each assay are distributed against the ELISpot activity $(\mathrm{sfc} / \mathrm{m})$. The distribution of medium controls from all assays using CSP or AMA1 peptide pools, and the total using both antigens, show the same distribution. v1039 and v1041 were consistently positive only at a single time point (Figure 5, details in Additional File 6). When positive responses to AMA1 were combined, v1039, v1054 and v1056 were consistently positive (positive in all three assays) at both time points, and v1001 and v1024 were consistently positive at one time point. v1036 was positive in both available samples at the first time-point. The remaining assays were positive at one or two of three assays at a given time-point.

\section{Negative volunteers}

With CSP v1036 was consistently negative (0/3 assays) at both time-points and 1024 and v1056 were consistently negative at single time-points. None were consistently negative with AMA1.

\section{Positive peptide pools}

When responses to individual peptide pools were examined (Table 7, details in Additional File 6), Cp1 was the most frequently positive CSP peptide pool (16/30, 53\%) whereas other CSP peptide pools were less frequently positive. For AMA1, five volunteers (v1024, v1036, v1039, v1054 and v1056) recognized Ap7 and Ap9 in 40 of the total 84 positive assays (47.6\%), and only one of the 30 positive assays were not positive with Ap7 and Ap9 combined. Activities to Ap7 and Ap9 (that do not overlap) appeared to be linked $\left(R^{2}=0.63\right.$, Chi-square, two-tailed $\mathrm{p}=0.79)$ whereas no other peptide pools were similarly linked (Figure 6 ). The $6^{\text {th }}$ volunteer (v1001) primarily recognized Ap4 and Ap8 in 3/6 assays.

\section{Method 2}

The second method used Student's $t$ test, a ratio of test wells to medium controls of greater than two, and a greater than $10 \mathrm{sfc} / \mathrm{m}$ difference over medium control and was also used in Part A.

\section{Positive volunteers}

This method identified 17/324 (5.2\%) CSP and 62/420 (14.8\%) AMA1 assays as positive (Table 7 , details in Additional File 7), and these frequencies were lower than using Method 1. This method identified consistent results with CSP (3/3 assays positive) with v1054 (both time points) and with AMA1 with v1054 and v1056 (both time points positive) and v1039 (single time points) and v1036 (2 positive assays of 2 available samples) (Figure 5, details in Additional File 7).

\section{Negative volunteers}

v1056 was consistently negative (0/3 assays) at both time points with CSP, and v1024, v1036 and v1041 were consistently negative at one time-point. However, no volunteers were consistently negative with AMA1.

\section{Positive peptide pools}

For CSP, only Cp1 and Cp9 induced positive activities, and most were induced by $\mathrm{Cp} 1$ (13/17 and $76.5 \%$, respectively, Figure 5, details in Additional File 7). For AMA1, Ap7 and Ap9 together induced most positive 
Table 7 Summary of assays with positive ELISpot activities using statistical Methods 1, 2 and 3

\begin{tabular}{ccccccc}
\hline & \multicolumn{2}{c}{ CSP } & \multicolumn{3}{c}{ AMA1 } \\
\hline Method & Assays & No. Positive & Cp1* & Assays & No. Positive & Ap7and9** \\
\hline$>$ Med & 324 & $138(42.6 \%)$ & $30 / 138(21.7 \%)$ & 420 & $236(56.2 \%)$ & $53 / 201(26.3 \%)$ \\
\hline $\mathbf{1}$ & 324 & $30(9.3 \%)$ & $16 / 30(53.0 \%)$ & 420 & $94(22.4 \%)$ & $40 / 84(47.6 \%)$ \\
\hline $\mathbf{2}$ & 324 & $17(5.2 \%)$ & $13 / 17(76.5 \%)$ & 420 & $62(14.8 \%)$ & $34 / 57(60.0 \%)$ \\
\hline $\mathbf{3}$ & 324 & $10(3.1 \%)$ & $9 / 10(90 \%)$ & 420 & $41(9.8 \%)$ & $29 / 36(80.1 \%)$ \\
\hline
\end{tabular}

ELISpot activities >medium controls were analysed using Methods 1, 2 and 3 (see Methods) and the positive activities for each method are shown. The numbers of $\mathrm{Cp} 1$ are for all volunteers tested, Ap7+Ap9 excluding v1001 who responded to different peptide pools. * Proportion of positive assays that are positive by Cp1; ** Proportion of positive assays that are positive by Ap7 or Ap9 excluding v1001.

activities for 5 volunteers excluding v1001 (34/57 and $60.0 \%$, respectively), and other AMA1 peptide pools were only positive when Ap7 and Ap9 were positive. v1001 only recognized Ap4 and Ap8.

\section{Method 3}

This was the most stringent and used two criteria: 55 $\mathrm{sfc} / \mathrm{m}$ as a minimum cut off and a 4-fold or greater difference between test wells and medium controls.

\section{Positive volunteers}

This method identified 10/324 (3.1\%) CSP and 41/420 (9.8\%) AMA1 positive assays (Table 7, details in Additional File 5), and these were lower than using Methods 1 or 2 . This method gave the lowest frequency of consistent outcomes (all three sets at either time point). v1054 was positive with CSP and AMA1 with all three assays at both time points; v1039 and v1056 gave consistent positives with AMA1 in all assays at one time point, and v1036 was positive with both available samples at one time-point (Figure 5, details in Additional File 5).

\section{Negative volunteers}

With CSP, v1024, v1036 and v1056 were consistently negative (0/3 assays) at both time points, and v1039 and v1041 were consistently negative at one time-point. Only v1036 was consistently negative with AMA1 at one time point.

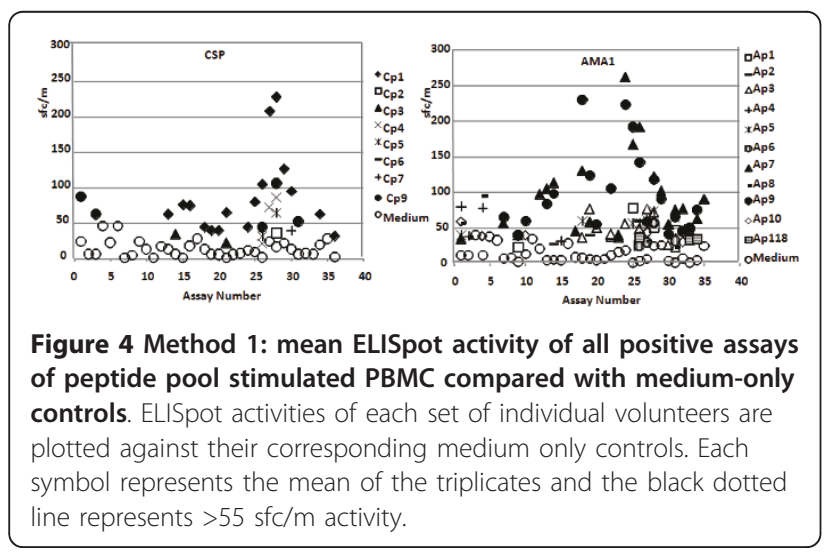

\section{Positive peptide pools}

For CSP, Cp1 induced 9/10 positive activities (90\%) and Cp1 induced 1 positive activity. With AMA1 29/36 (80.1\%) were positive with Ap7 and Ap9 combined, excluding v1001 (Table 7, details in Additional File 5). The numbers of positive assays with Ap7 and Ap9 were least affected by increasing the stringency of the analytical method used.

\section{Combined ELISpot responses to CSP and AMA1}

CSP and AMA1 responses were added together (Figure 5) for those 5 volunteers who were tested with both peptides (v1024, v1036, v1039, v1054 and v1056). Since both samples of v1036 at one time-point were consistently positive with AMA1 it was included within the 3/ 3 positive group to give 10 time-points. The consistent (3/3 and $0 / 3)$ and the inconsistent outcomes $(2 / 3$ and $1 /$ 3 ) were combined (Figure 7). Method 1 gave the greatest numbers of consistent (80\%) and fewest numbers of inconsistent (20\%) outcomes compared to Methods 2 and 3 (60\% and $40 \%$ consistent, respectively).

\section{Comparison of the Two Time Points}

There was only modest consistency when two time points approximately two weeks apart were compared. Each time point was classified as positive (3/3 assays positive), negative ( $0 / 3$ assays positive) or indeterminate ( $2 / 3$ or $1 / 3$ assays positive), then the number of positive, negative or indeterminate results that were concordant between the two time points were calculated. For Method 1 the number of consistent assays that were positive, negative or indeterminate were 4,1 and 0 , respectively or $5 / 12$ overall (both antigens); for Method 2 : the numbers were 3,1 and 2 , respectively, or $6 / 12$ overall; and for Method 3: the numbers were 2, 3 and 2, respectively, or $7 / 12$ overall. Thus, overall, in only about half the cases were the results at one time-point reproduced at the second time point two weeks later.

\section{Discussion}

Malaria vaccine development is focused on a variety of candidate antigens including those in this study. In particular, prime-boost strategies designed to elicit 


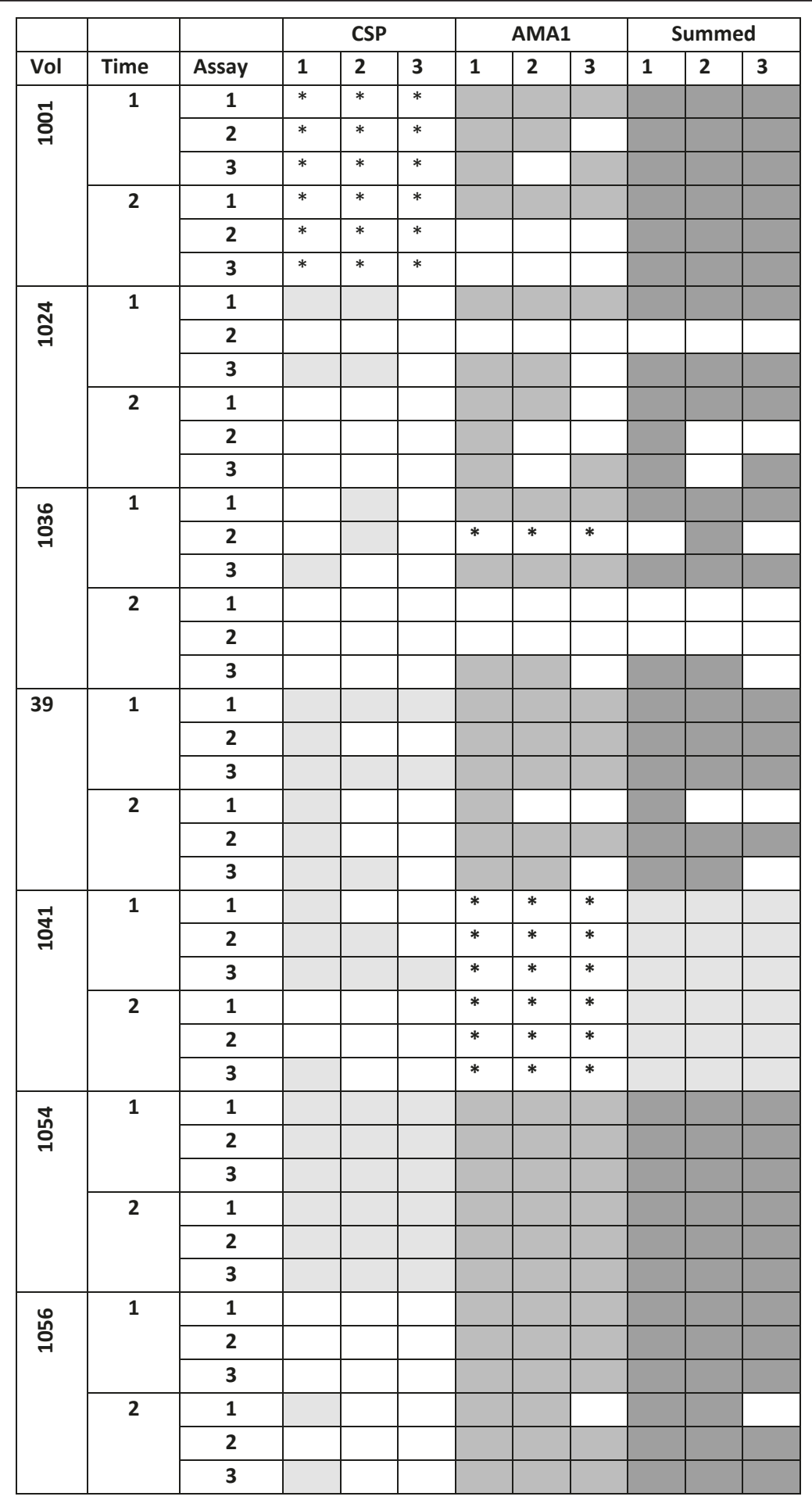

Figure 5 Positive ELISpot activities with CSP or AMA1 peptide pools with Methods $\mathbf{1 ,} \mathbf{2}$ or $\mathbf{3}$. The top three rows for each volunteer denote the three replicate assays for the first time point, and the second three rows denote the three replicate assays for the second timepoint. An assay is considered positive if at least one peptide pool was positive using that method. All positive CSP and AMA1 activities are shown in light or medium gray respectively. The responses of the five volunteers (v1024, v1036, v1039, v1054 and v1056, for whom both CSP and AMA1 assays were performed) were combined and shown in dark gray. *Assay not done. 


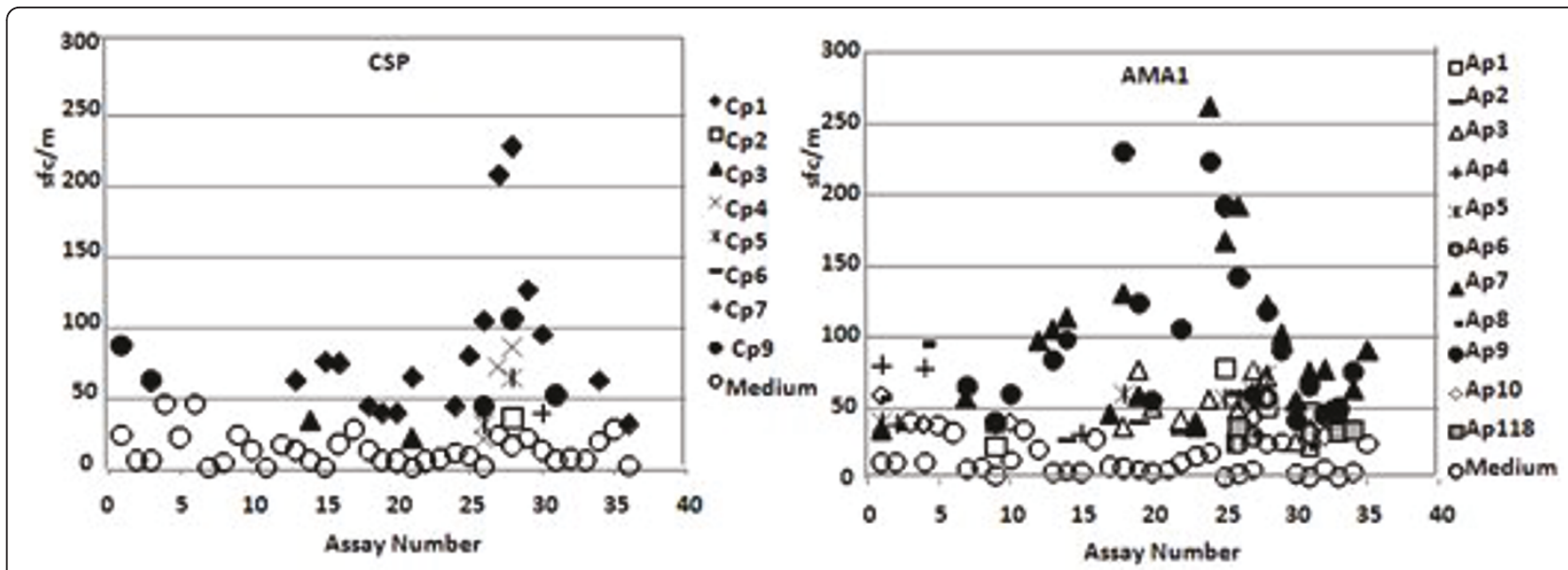

Figure 6 Method 1: Linkage of ELISpot activities. Left panel: ELISpot activities of Ap7 and Ap9 show moderate linkage $\left(r^{2}=0,63\right)$. Right panel: no linkage between Ap7 and Cp1 $\left(r^{2}=0.03\right)$.

antibodies and especially $\mathrm{T}$ cell responses associated with protection are moving to immunogenicity and efficacy studies in endemic populations. A long-term goal of these studies is to establish antibody and $\mathrm{T}$ cell assays at sites in Southern Ghana that might be used for clinical trials[51,52]. To achieve this there were two aims. Firstly (Part A) to establish the ELISA, IFA and ELISpot assays at this study site, and secondly (Part B) to develop the ELISpot assay best suited to test potential vaccine cohorts especially where naturally-acquired activities are low and without requiring HLA typing of the volunteers. ELISpot assays have been used widely in

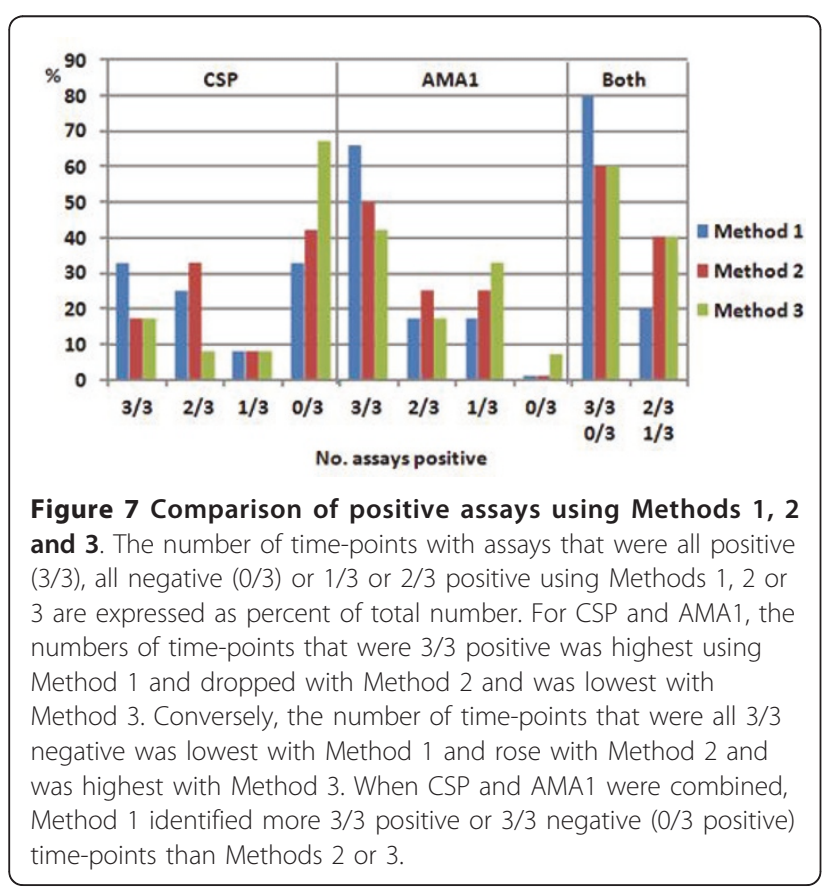

measuring vaccine-induced $\mathrm{T}$ cell activities in non-endemic populations where background (pre-immunization) activities are usually low compared to those in malariaendemic populations, and there is little information concerning the reproducibility of ELISpot assays in endemic populations.

\section{Antibody assays}

Using a panel of recombinant proteins representing seven candidate vaccine antigens, ELISA detected relatively low antibody responses that trended higher in rural Mampong-Akwapim than urban Accra, a difference that was statistically significant only for MSP3, suggesting that the higher malaria prevalence in the rural population had only a marginal association with increased antibody responses to most antigens. IFA assays detected anti-sporozoite and anti-red blood cell antibodies with roughly equal frequency in volunteers from the two study sites, and IFA titres correlated with ELISA activities. Most adults possessed demonstrable anti-malaria antibodies as would be expected in an endemic adult population (see for example[30,53,54] where malaria transmission occurs throughout the year). When two criteria of lower and higher stringency were used to classify ELISA responses as positive or negative, all volunteers were positive to at least one antigen using either method. However, positive responses to the preerythrocytic antigen CSP, but not SSP2/TRAP, were rare in urban volunteers compared to rural volunteers, perhaps indicating that rural volunteers were being bitten more frequently by infected mosquitoes. The numbers of positive antigens decreased when stringency increased particularly with CSP. This analysis may suggest that the lower stringency analysis was more useful to distinguish rural and urban communities with regard to pre- 
erythrocytic antigens. This may be supported by the observation that positive ELISA activities to these antigens using the lower stringency analysis were more concordant with ELISpot activities (see below). The importance of defining antibody titers in naturallyacquired immunity has been underscored by recent longitudinal studies that established correlations between higher IgG levels to several antigens tested in this study and reduced risk of clinical malaria in Northern Ghana[55,56], Kenya[57] and Burkina Faso[53].

\section{ELISpot assays (using HLA-matched peptides)}

Since $\mathrm{T}$ cell responses to malaria antigens are often HLA-restricted[36,37], it seemed likely that the greatest sensitivity of the ELISpot assay would be achieved using HLA-matched peptides with appropriate length for stimulating Class I or Class II responses. To define background ELISpot responses to five candidate malaria vaccine antigens, Method 2 was used to identify positive outcomes. The criteria required a statistically significant difference between replicate test (peptide stimulated) wells and medium-only control wells (Students $t$ test) and at least a two-fold, $10 \mathrm{sfc} /$ million difference.

The numbers of urban and rural volunteers who were positive with long DR or short HLA A or B peptides was similar, although rural volunteers recognized more antigens than urban volunteers. However, CSP responses were rare, with a higher frequency of responses to LSA1 or SSP2/TRAP, particularly to DR-restricted peptides, in both urban and rural areas. This may reflect different transmission patterns in these two sites as increased transmission in the rural site may induce higher frequency of CSP responses. The average of all positive responses was $>70 \mathrm{sfc} / \mathrm{m}$, and some responses were as high as $430 \mathrm{sfc} / \mathrm{m}$. An earlier study showed that ELISpot responses to non-HLA-matched CSP peptides in The Gambia were very low, $23+11 \mathrm{sfc} / \mathrm{m}$ [58], suggesting that HLA-matched peptides and volunteers may be a more sensitive assay of ELISpot responses than using individual non-matched peptides. As in other studies[25], malaria infection appeared to suppress ELISpot responses to short peptides, suggesting that the frequency of volunteers, particularly in rural areas, with class I-restricted ELISpot responses may be underestimated.

One of the challenges associated with using this approach is determining the appropriate peptides to test. We selected peptides based on the HLA of the volunteers and the availability of HLA-matched peptides. DR-binding epitopes are relatively promiscuous and bind to more than one DR haplotype [59-62], and all volunteers were tested against 5 DR peptides regardless of HLA type, although an additional 4 DR peptides were matched to a subset of volunteers based on HLA A or B epitopes contained within them. Utilizing the peptides available, only about half of the volunteers could be tested with HLA A and B matched short peptides; thus it is difficult to know if response rates might have been significantly higher had more epitopes been synthesized and tested. In addition, matching was performed on the basis of HLA type without taking into account supertype, which could have allowed a larger number of peptides to be matched to each volunteer. Overall, this approach was cumbersome and led to a complex experimental design (Additional Files 7 \&8) that likely contributed to underestimating the frequency of positive responses.

\section{Analysis of reproducibility (using overlapping peptides)}

The second aim was to determine the reproducibility of the ELISpot assay. Due to the challenges associated with using HLA-matched peptides, an alternative approach was adopted for Part B - to test all volunteers against uniform pools of overlapping peptides without HLA testing, on the assumption that such peptides would contain all $\mathrm{T}$ cell epitopes that could be recognized by the volunteers and that the uniform, 15 amino acid length would elicit Class I or Class II responses. The apparent dependence of CD8+ $\mathrm{T}$ cell responses to plasmodial antigens on $\mathrm{CD} 4+\mathrm{T}$ cells $([37,63-65]$ may reflect that CD4+ and CD8+ T epitopes often overlap.

Usually ELISpot assays are performed once, using replicate wells. However, it is uncertain whether a single assay accurately represents $\mathrm{T}$ cell activities, especially in an area where they are low. To address this, two blood samples were drawn from each volunteer approximately two weeks apart, PBMC were frozen and then tested in three assays on different days. If the ELISpot assay is reproducible then all three assays at a single time point should be either all positive or all negative.

\section{Ex vivo ELISpot assays - analysis of reproducibility}

Of critical importance in determining ELISpot reproducibility are the criteria used to identify which of the relatively low, infrequent and unstable ELISpot responses induced by malaria transmission[7-9,28] should be considered positive. Unlike vaccine trials, where post-immunization responses are differentiated by comparison with pre-immunization samples, naturally-acquired responses can only be differentiated by comparison with mediumonly controls. Analysis of ELISpot responses using peptide pools was complex as about half of all responses were within the range of medium-only controls. In that case, the choice of statistical analysis to determine positive activities was crucial. Such analyses identify a cut off value above which an activity is considered positive. If the cut off is low more activities are likely to be determined to be positive than using a high cut off. To explore this effect, three statistical methods of increasing stringency were applied. The least stringent method 
(Method 1, difference of $20 \mathrm{sfc} / \mathrm{m}$ between medium control and test sample) gave the greatest number of consistently positive (3/3) assays and the fewest where $1 / 3$ or $2 / 3$ were positive (Figure 7 ). More stringent analyses such as the Student's $t$ test that has been used in vaccine trials[48] and was used in Part A, or a defined ELISpot activity that was four times and at least $55 \mathrm{sfc} /$ million greater than the median of medium only controls[35], identified fewer positive assays and fewer instances when three replicate assays were consistently positive. Overall, the least stringent method yielded $80 \%$ consistent results while the other two yielded $60 \%$ consistent results, indicating that at least in this population, a simple assessment relying on a $20 \mathrm{sfc} /$ million difference may be most suitable.

More volunteers were positive with AMA1 than CSP, consistent with previous studies that $\mathrm{T}$ cell immunity to blood stage antigens was detected in $67 \%$ of individuals [8] and less frequently with pre-erythrocytic antigens $[9,28]$. Although not an objective of this study, this high frequency of $\mathrm{T}$ cell responses to AMA1 may be associated with the effect of naturally acquired immunity on reducing severe disease[66].

Three peptide pools appeared to detect responses in most volunteers; Cp1, Ap7 and Ap9. Cp1 is known to contain HLA-A02, HLA-A24 and HLA-B44 T cell epitopes $[36,64]$, Ap7 and Ap9 also contain previously identified proliferative epitopes[24], and Ap7 also contains a CD8+ $\mathrm{T}$ cell restricted epitope[31]. The $\mathrm{Cp} 1$ responses were consistent with those elicited by the mixture of HLA-A02restricted D4 and D5 as D4 is contained within the peptides in Cp1. In Part A using HLA-matched peptides a total of $2 / 13$ urban volunteers showed positive responses, whereas 3/6 volunteers in Part B showed positive responses with CSP peptide pools. Although ELISpot activities of both Part A and B with peptides or peptide pools were similar (fresh cells were used in Part A and frozen cells in Part B), peptide pools may elicit positive responses in more volunteers than HLA-matched peptides. This is not surprising as $\mathrm{Cp} 1$ contains at least 3 known HLA-restricted epitopes and may thus be better able to detect responses in a wider population than using a few HLA-matched peptide epitopes. Responses to Ap7 and Ap9 appeared to be linked and both pools appeared to contain immunodominant epitopes,

It remains to be demonstrated whether vaccines induce the same dominant responses in volunteers in malaria-endemic areas as have been induced in those volunteers through natural transmission. Thus, in any potential vaccine trials in Ghana, ELISpot assays may have to be further refined to distinguish vaccine-induced $\mathrm{T}$ cell immunity from that naturally acquired.

ELISpot responses varied significantly over even short periods of time. When the proportion of consistently positive and consistently negative assays were compared between the two time points, which were separated by just two weeks, only in about half the cases were the outcomes the same. This is consistent with the findings in other studies that $\mathrm{T}$ cell responses are relatively unstable over time[ $8,28,50]$. It is not possible to quantify the degree to which these differences may have been affected by assay variation.

Recently, some of the most powerful studies have used protein arrays to measure the responses to many antigens simultaneously, identifying antigen clusters for which immunological recognition may imply clinical resistance to malaria[67,68] and this approach may be highly applicable to further studies at the sites in Ghana. The interpretation of array data faces the same questions regarding criteria for positivity as addressed in the current study.

\section{Conclusions}

This study demonstrated that antibody assays, ELISA and IFA, could successfully measure antibodies in Ghana to malaria antigens undergoing vaccine development. Likewise, the ex vivo ELISpot assay was shown to reproducibly measure T cell IFN- $\gamma$ activities despite responses being low and variable, but reproducibility depended partly on the statistical method used to determine positive activities. Due to ease of use, overlapping peptides appeared to be preferable to HLA typing and the use of HLA-matched peptides. For ELISA, the more stringent criteria for positivity may have better distinguished rural and urban populations, at least for pre-erythrocytic stage antigens. For ELISpot, the least stringent method tended to yield the most consistently reproducible outcomes. For both humoral and cellular assays, further work is needed to demonstrate the generalizability of these findings. Better understanding of how to conduct these assays in endemic areas is important given the requirement for their use in malaria vaccine studies at these sites.

\section{Additional material}

Additional File 1: Part A: Volunteers tested in IFA, ELISA and

ELISpot Assay. Thirty five volunteers met selection criteria and were used in antibody (IFA and ELISA) assays. Thirty of these volunteers were HLA-typed and used in ELISpot assays.

Additional File 2: Positive ELISA activities defined using Method 1 Positive ELISA activities were defined as the mean Ghanaian volunteer $\mathrm{OD} \geq$ mean control sera +3 SD. Shaded cells show positive assays with each antigen. The numbers of positive assays per volunteer, the total number of positive assays for urban and rural populations and the mean number of positive assays/volunteer for each population are shown in the two right columns. The total numbers of urban and rural volunteers positive with each protein are shown in the bottom rows. A "+" next to the volunteer identification number in the second column indicates patent parasitemia at the time the sample was taken [see Methods]. Volunteers tested in ELISpot assays using DR-binding or HLA A and B- 
matched peptides shown by X and @ (Tables 3 and 4), and these indicate positive assays with each volunteer.

Additional File 3: Positive ELISA activities defined using Method 2 Positive ELISA activities were defined as the mean Ghanaian volunteer $O D \geq$ mean control sera $+3 S D$ and at minimum titer of 100 . Shaded cells show positive assays with each antigen. The numbers of positive assays per volunteer, the total number of positive assays for urban and rural populations and the mean number of positive assays/volunteer for each population are shown in the two right columns. The total numbers of urban and rural volunteers positive with each protein are shown in the bottom rows. A " + " next to the volunteer identification number in the second column indicates patent parasitemia at the time the sample was taken [see Methods]. Volunteers tested in ELISpot assays using DRbinding or HLA A and B-matched peptides shown by X and @ (Tables 3 and 4$)$, and these indicate positive assays with each volunteer.

Additional File 4: Part A: Sequences of all short and long peptides tested in ELISpot assays. Peptides were either used alone or in mixtures as indicated by horizontal divisions in the second and last columns. Each was assigned a number (last column) that was used to identify which was tested with each volunteer (Additional Table 5). Shaded cell indicate peptides or peptide mixture that elicited positive ELISpot activities in at least one volunteer. *Peptides D44 and D49 were used together.

Additional File 5: Urban and rural volunteers: HLA-A and HLA-B supertypes and HLA matched peptides. Volunteers had low to medium resolution HLA typing (see Methods) and tested with HLAmatched peptides (gray cells). DR of each volunteer is not shown. Positive assays are shown in black cells. ${ }^{*}$ Uncertain assignment. NA Not available. To identify the peptides for each column, refer to Additional Table 4 using the reference number provided in the second row (1-27).

\section{Additional File 6: ELISpot activities to CSP or AMA1 peptide pools}

in replicate assays using Method 1. ELISpot activities were determined by subtracting the medium controls from the test peptide pool, and used an arbitrary cut off of a net value of $20 \mathrm{sfc} / \mathrm{m}$. Positive outcomes for each set are shown in light gray (CSP) and medium gray (AMA1); individual activities were combined to give a total CSP ( $C$, light gray) or AMA1 ( $A$, medium gray) response. $V=$ volunteer ID; $T=$ time-point; $A=$ assay number. The first three rows for each volunteer are the three assays for the first time-point, while the second three rows are the assays for the second time point. Missing samples are indicated by dots.

\section{Additional File 7: ELISpot activities to CSP or AMA1 peptide pools}

in replicate assays using Method 2. ELISpot activities were determined using the Student's $t$ test to analyze specific differences $(p=<0.05$, two tailed) between test peptide pool and medium controls, and were considered positive if the test activity was at least twice that of the medium controls and the difference was at least $10 \mathrm{sfc} / \mathrm{m}$. Positive outcomes for each set are shown in gray; individual activities were combined to give a total CSP ( $C$, light gray) or AMA1 ( $A$, medium gray) response. $V=$ volunteer ID; $T$ = time-point; $A$ = assay number. The first three rows for each volunteer are the three assays for the first timepoint, while the second three rows are the assays for the second time point. Missing samples are indicated by dots.

Additional File 8: ELISpot activities to CSP or AMA1 peptide pools in replicate assays using Method 3. ELISpot activities were positive if the median of peptide pools was $>55 \mathrm{sfc} / \mathrm{m}$ and at least four times the median of the medium controls. Positive outcomes for each set are shown in gray; individual activities were combined to give a total CSP (C, light gray) or AMA1 (A, medium gray) response. $V=$ volunteer $I D ; T=$ time-point; $\mathrm{A}=$ assay number. The first three rows for each volunteer are the three assays for the first time-point, while the second three rows are the assays for the second time point. Missing samples are indicated by dots.

\section{Acknowledgements and Funding}

The studies were supported by U.S. Naval Medical Research Center work unit number 6000.RAD1.F.A0309 and National Institutes of Allergy and Infectious
Diseases, National Institutes of Health contract NO1 Al95363. We thank David Lanar and David Narum for the gift of recombinant $P$. falciparum proteins and John Arko-Mensah and Eric Kyei-Baafour for technical assistance. The study was approved by the Institutional Review Boards of the Noguchi Memorial Institute for Medical Research and the U.S. Naval Medical Research Center and conducted in accordance with the International Conference on Harmonisation (ICH), current Good Clinical Practices (CGCP), and U.S. Navy regulations (SECNAVINST 3900.39B) governing the use of human subjects in medical research. The views expressed herein are the personal ones of the authors and do not purport to reflect the views of the U.S. Navy, the Department of Defense, or the Food and Drug Administration.

\section{Author details}

'Noguchi Memorial Institute for Medical Research, University of Ghana, Legon, Ghana. ${ }^{2}$ Consultant to the US Military Malaria Vaccine Program, Naval Medical Research Center, Silver Spring, MD 20910, USA. ${ }^{3}$ WHO Regional Office for Africa, Brazzaville, Congo Republic. ${ }^{4}$ US Military Malaria Vaccine Program, Naval Medical Research Center, Silver Spring, MD 20910, USA. ${ }^{5}$ RTI Rockville, Rockville, MD 20852, USA. ${ }^{6}$ Center for Biologics Review and Research, Food and Drug Administration, Rockville, MD 20892, USA. ${ }^{7}$ Naval Medical Research Unit \#3, Cairo, Egypt. ${ }^{8}$ Queensland Institute for Medical Research, Brisbane, QLD Australia.

\section{Authors' contributions}

Conceived the study: MS, WOR and KAK; Designed the experiments: MS, TR, WOR, JE, DD, KAK, BDA; Served as Principal investigators: DD and MS; Served as Investigators: KAK, JO, BDA, BG, and JE; Performed Immunological assays: DD, MS, DA, HG, SA, JL, GB, RS; Provided recombinant proteins: SK; Performed statistical analyses: DB and MRH; Wrote the manuscript: WOR, $M R H, M S$, and TLR. All authors read and approved the final manuscript.

\section{Competing interests}

The authors declare that they have no competing interests.

Received: 12 April 2011 Accepted: 20 June 2011

Published: 20 June 2011

\section{References}

1. Todryk SM, Bejon P, Mwangi T, Plebanski M, Urban B, Marsh K, Hill AV, Flanagan KL: Correlation of memory T cell responses against TRAP with protection from clinical malaria, and CD4 CD25 high T cells with susceptibility in Kenyans. PLOS ONE 2008, 3:e2027.

2. Fowkes FJ, Richards JS, Simpson JA, Beeson JG: The relationship between anti-merozoite antibodies and incidence of Plasmodium falciparum malaria: A systematic review and meta-analysis. PLoS Med 7:e1000218.

3. John CC, Tande AJ, Moormann AM, Sumba PO, Lanar DE, Min XM, Kazura JW: Antibodies to pre-erythrocytic Plasmodium falciparum antigens and risk of clinical malaria in Kenyan children. J Infect Dis 2008, 197:519-526.

4. Webster HK, Boudreau EF, Pang LW, Permpanich B, Sookto P, Wirtz RA: Development of immunity in natural Plasmodium falciparum malaria: antibodies to the falciparum sporozoite vaccine 1 antigen (R32tet32). J Clin Microbiol 1987, 25:1002-1008.

5. Charoenvit Y, Leef MF, Yuan LF, Sedegah M, Beaudoin RL: Characterization of Plasmodium yoelii monoclonal antibodies directed against stagespecific sporozoite antigens. Infect Immun 1987, 55:604-608.

6. Irion A, Beck HP, Smith T: Assessment of positivity in immuno-assays with variability in background measurements: a new approach applied to the antibody response to Plasmodium falciparum MSP2. J Immunol Methods 2002, 259:111-118.

7. Moormann AM, Sumba PO, Tisch DJ, Embury P, King CH, Kazura JW, John CC: Stability of interferon-gamma and interleukin-10 responses to Plasmodium falciparum liver stage antigen 1 and thrombospondinrelated adhesive protein immunodominant epitopes in a highland population from Western Kenya. Am J Trop Med Hyg 2009, 81:489-495.

8. Dent AE, Chelimo K, Sumba PO, Spring MD, Crabb BS, Moormann AM, Tisch DJ, Kazura JW: Temporal stability of naturally acquired immunity to Merozoite Surface Protein-1 in Kenyan adults. Malar J 2009, 8:162.

9. Flanagan KL, Mwangi T, Plebanski M, Odhiambo K, Ross A, Sheu E, Kortok M, Lowe B, Marsh K, Hill AV: Ex vivo interferon-gamma immune response to thrombospondin-related adhesive protein in coastal 
Kenyans: longevity and risk of Plasmodium falciparum infection. Am J Trop Med Hyg 2003, 68:421-430.

10. Riley EM, Allen SJ, Bennett S, Thomas PJ, O'Donnell A, Lindsay SW, Good MF, Greenwood BM: Recognition of dominant T cell-stimulating epitopes from the circumsporozoite protein of Plasmodium falciparum and relationship to malaria morbidity in Gambian children. Trans $R$ SOC Trop Med Hyg 1990, 84:648-657.

11. Udhayakumar V, Ongecha JM, Shi YP, Aidoo M, Orago AS, Oloo AJ, Hawley WA, Nahlen BL, Hoffman SL, Weiss WR, et al: Cytotoxic T cell reactivity and HLA-B35 binding of the variant Plasmodium falciparum circumsporozoite protein CD8+ CTL epitope in naturally exposed Kenyan adults. Eur J Immunol 1997, 27:1952-1957.

12. Hill AV, Elvin J, Willis AC, Aidoo M, Allsopp CE, Gotch FM, Gao XM, Takiguchi M, Greenwood BM, Townsend AR, et al: Molecular analysis of the association of HLA-B53 and resistance to severe malaria. Nature 1992, 360:434-439

13. Sedegah M, Sim BK, Mason C, Nutman T, Malik A, Roberts C, Johnson A, Ochola J, Koech D, Were B, et al: Naturally acquired CD8+ cytotoxic T lymphocytes against the Plasmodium falciparum circumsporozoite protein. J Immunol 1992, 149:966-971.

14. Crisanti A, Muller HM: The human immune response against the major merozoite surface antigen of Plasmodium falciparum. Parassitologia 1991, 33:71-77.

15. Diallo TO, Nguer CM, Dieye A, Spiegel A, Perraut R, Garraud O: Immune responses to $P$. falciparum-MSP1 antigen: lack of correlation between antibody responses and the capacity of peripheral cellular immune effectors to respond to this antigen in vitro. Immunol Lett 1999, 67:217-221.

16. Lee EA, Flanagan KL, Odhiambo K, Reece WH, Potter C, Bailey R, Marsh K, Pinder M, Hill AV, Plebanski M: Identification of frequently recognized dimorphic T-cell epitopes in plasmodium falciparum merozoite surface protein-1 in West and East Africans: lack of correlation of immune recognition and allelic prevalence. Am J Trop Med Hyg 2001, 64:194-203.

17. Lee EA, Palmer DR, Flanagan KL, Reece WH, Odhiambo K, Marsh K, Pinder M, Gravenor MB, Keitel WA, Kester KE, et al: Induction of T helper type 1 and 2 responses to 19-kilodalton merozoite surface protein 1 in vaccinated healthy volunteers and adults naturally exposed to malaria. Infect Immun 2002, 70:1417-1421.

18. Sanni LA, Allsopp CE, Reubsaet L, Sanni A, Newbold C, Chauhan VS, Langhorne J: Cellular responses to Plasmodium falciparum erythrocyte membrane protein-1: use of relatively conserved synthetic peptide pools to determine CD4 T cell responses in malaria-exposed individuals in Benin, West Africa. Malar J 2002, 1:7

19. Shi YP, Sayed U, Qari SH, Roberts JM, Udhayakumar V, Oloo AJ, Hawley WA, Kaslow DC, Nahlen BL, Lal AA: Natural immune response to the Cterminal 19-kilodalton domain of Plasmodium falciparum merozoite surface protein 1. Infect Immun 1996, 64:2716-2723.

20. Lalvani A, Hurt N, Aidoo M, Kibatala P, Tanner M, Hill AV: Cytotoxic T lymphocytes to Plasmodium falciparum epitopes in an area of intense and perennial transmission in Tanzania. Eur J Immunol 1996, 26:773-779.

21. Plebanski M, Aidoo M, Whittle HC, Hill AV: Precursor frequency analysis of cytotoxic T lymphocytes to pre-erythrocytic antigens of Plasmodium falciparum in West Africa. J Immunol 1997, 158:2849-2855.

22. Aidoo M, Lalvani A, Gilbert SC, Hu JT, Daubersies P. Hurt N, Whittle HC, Druihle P, Hill AV: Cytotoxic T-lymphocyte epitopes for HLA-B53 and other HLA types in the malaria vaccine candidate liver-stage antigen 3. Infect Immun 2000, 68:227-232.

23. Udhayakumar V, Kariuki S, Kolczack M, Girma M, Roberts JM, Oloo AJ, Nahlen BL, Lal AA: Longitudinal study of natural immune responses to the Plasmodium falciparum apical membrane antigen (AMA-1) in a holoendemic region of malaria in western Kenya: Asembo Bay Cohort Project VIII. Am J Trop Med Hyg 2001, 65:100-107.

24. Lal AA, Hughes MA, Oliveira DA, Nelson C, Bloland PB, Oloo AJ, Hawley WE, Hightower AW, Nahlen BL, Udhayakumar V: Identification of T-cell determinants in natural immune responses to the Plasmodium falciparum apical membrane antigen (AMA-1) in an adult population exposed to malaria. Infect Immun 1996, 64:1054-1059.

25. Bejon P, Mwacharo J, Kai O, Todryk S, Keating S, Lowe B, Lang T, Mwangi TW, Gilbert SC, Peshu N, et al: The induction and persistence of T cell IFN-gamma responses after vaccination or natural exposure is suppressed by Plasmodium falciparum. J Immunol 2007, 179:4193-4201.
26. Romero P, Cerottini JC, Waanders GA: Novel methods to monitor antigenspecific cytotoxic T-cell responses in cancer immunotherapy. Mol Med Today 1998, 4:305-312

27. Gonzalez JM, Peter K, Esposito F, Nebie I, Tiercy JM, Bonelo A, ArevaloHerrera M, Valmori D, Romero P, Herrera S, et al: HLA-A*0201 restricted CD8+ T-lymphocyte responses to malaria: identification of new Plasmodium falciparum epitopes by IFN-gamma ELISPOT. Parasite Immunol 2000, 22:501-514.

28. Flanagan KL, Plebanski M, Odhiambo K, Sheu E, Mwangi T, Gelder C, Hart K, Kortok M, Lowe B, Robson K, et al: Cellular reactivity to the p. Falciparum protein trap in adult kenyans: novel epitopes, complex cytokine patterns, and the impact of natural antigenic variation. Am J Trop Med Hyg 2006, 74:367-375.

29. Malhotra I, Wamachi AN, Mungai PL, Mzungu E, Koech D, Muchiri E, Moormann AM, King CL: Fine specificity of neonatal lymphocytes to an abundant malaria blood-stage antigen: epitope mapping of Plasmodium falciparum MSP1(33). J Immunol 2008, 180:3383-3390.

30. Spring MD, Chelimo K, Tisch DJ, Sumba PO, Rochford R, Long CA, Kazura JW, Moormann AM: Allele specificity of gamma interferon responses to the carboxyl-terminal region of Plasmodium falciparum merozoite surface protein 1 by Kenyan adults with naturally acquired immunity to malaria. Infect Immun 78:4431-4441.

31. Sedegah M, Kim Y, Peters B, McGrath S, Ganeshan H, Lejano J, Abot E, Banania G, Belmonte M, Sayo R, et al: Identification and localization of minimal MHC-restricted CD8+ T cell epitopes within the Plasmodium falciparum AMA1 protein. Malar / 9:241.

32. Woodberry $T$, Pinzon-Charry A, Piera KA, Panpisutchai $Y$, Engwerda $C R$, Doolan DL, Salwati E, Kenangalem E, Tjitra E, Price RN, et al: Human T cell recognition of the blood stage antigen Plasmodium hypoxanthine guanine xanthine phosphoribosyl transferase (HGXPRT) in acute malaria. Malar J 2009, 8:122.

33. John CC, Moormann AM, Sumba PO, Ofulla AV, Pregibon DC, Kazura JW: Gamma interferon responses to Plasmodium falciparum liver-stage antigen 1 and thrombospondin-related adhesive protein and their relationship to age, transmission intensity, and protection against malaria. Infect Immun 2004, 72:5135-5142.

34. Hill AV, Elvin J, Willis AC, Aidoo M, Allsopp CE, Gotch FM, Gao XM, Takiguchi M, Greenwood BM, Townsend AR, et al: Molecular analysis of the association of HLA-B53 and resistance to severe malaria. Nature 1992, 360:434-439.

35. Fu TM, Dubey SA, Mehrotra DV, Freed DC, Trigona WL, Adams-Muhler L, Clair JH, Evans TG, Steigbigel R, Jacobson JM, et al: Evaluation of cellular immune responses in subjects chronically infected with HIV type 1. AIDS Res Hum Retroviruses 2007, 23:67-76.

36. Doolan DL, Hoffman SL, Southwood S, Wentworth PA, Sidney J, Chesnut RW, Keogh E, Appella E, Nutman TB, Lal AA, et al: Degenerate cytotoxic $T$ cell epitopes from P. falciparum restricted by multiple HLA-A and HLA-B supertype alleles. Immunity 1997, 7:97-112.

37. Doolan DL, Southwood S, Chesnut R, Appella E, Gomez E, Richards A, Higashimoto YI, Maewal A, Sidney J, Gramzinski RA, et al: HLA-DRpromiscuous T cell epitopes from Plasmodium falciparum preerythrocytic-stage antigens restricted by multiple HLA class II alleles. J Immunol 2000, 165:1123-1137.

38. Hisaeda H, Saul A, Reece JJ, Kennedy MC, Long CA, Miller LH, Stowers AW: Merozoite surface protein 3 and protection against malaria in Aotus nancymai monkeys. J Infect Dis 2002, 185:657-664.

39. Kumar S, Yadava A, Keister DB, Tian JH, Ohl M, Perdue-Greenfield KA, Miller $L H$, Kaslow DC: Immunogenicity and in vivo efficacy of recombinant Plasmodium falciparum merozoite surface protein-1 in Aotus monkeys. Mol Med 1995, 1:325-332

40. Kolodny N, Kitov S, Vassell MA, Miller VL, Ware LA, Fegeding K, De La Vega P, Sacci JB Jr, Lanar DE: Two-step chromatographic purification of recombinant Plasmodium falciparum circumsporozoite protein from Escherichia coli. J Chromatogr B Biomed Sci Appl 2001, 762:77-86.

41. Liang $H$, Narum DL, Fuhrmann SR, Luu T, Sim BK: A recombinant baculovirus-expressed Plasmodium falciparum receptor-binding domain of erythrocyte binding protein EBA-175 biologically mimics native protein. Infect Immun 2000, 68:3564-3568.

42. Khusmith S, Charoenvit Y, Kumar S, Sedegah M, Beaudoin RL, Hoffman SL: Protection against malaria by vaccination with sporozoite surface protein 2 plus CS protein. Science 1991, 252:715-718. 
43. Doolan DL, Hedstrom RC, Rogers WO, Charoenvit $Y$, Rogers $M$, de la Vega $P$, Hoffman SL: Identification and characterization of the protective hepatocyte erythrocyte protein $17 \mathrm{kDa}$ gene of Plasmodium yoelii, homolog of Plasmodium falciparum exported protein 1. J Biol Chem 1996, 271:17861-17868.

44. Spring MD, Cummings JF, Ockenhouse CF, Dutta S, Reidler R, Angov E, Bergmann-Leitner E, Stewart VA, Bittner S, Juompan L, et al: Phase 1/2a study of the malaria vaccine candidate apical membrane antigen-1 (AMA-1) administered in adjuvant system AS01B or AS02A. PLOS One 2009, 4:e5254

45. Charoenvit Y, Mellouk S, Cole C, Bechara R, Leef MF, Sedegah M, Yuan LF, Robey FA, Beaudoin RL, Hoffman SL: Monoclonal, but not polyclonal, antibodies protect against Plasmodium yoelii sporozoites. J Immunol 1991, 146:1020-1025.

46. Smith SG, Lalor MK, Gorak-Stolinska P, Blitz R, Beveridge NE, Worth A, McShane H, Dockrell HM: Mycobacterium tuberculosis PPD-induced immune biomarkers measurable in vitro following BCG vaccination of UK adolescents by multiplex bead array and intracellular cytokine staining. BMC Immunol 11:35

47. Todryk SM, Pathan AA, Keating S, Porter DW, Berthoud T, Thompson F, Klenerman $P$, Hill AV: The relationship between human effector and memory $T$ cells measured by ex vivo and cultured ELISPOT following recent and distal priming. Immunology 2009, 128:83-91.

48. Wang R, Epstein J, Baraceros FM, Gorak EJ, Charoenvit Y, Carucci DJ, Hedstrom RC, Rahardjo N, Gay T, Hobart P, et al: Induction of CD4(+) T cell-dependent $\mathrm{CD} 8(+)$ type 1 responses in humans by a malaria DNA vaccine. Proc Natl Acad Sci USA 2001, 98:10817-10822.

49. Charoenvit Y, Majam VF, Corradin G, Sacci JB Jr, Wang R, Doolan DL, Jones TR, Abot E, Patarroyo ME, Guzman F, et al: CD4(+) T-cell- and gamma interferon-dependent protection against murine malaria by immunization with linear synthetic peptides from a Plasmodium yoelii 17-kilodalton hepatocyte erythrocyte protein. Infect Immun 1999, 67:5604-5614.

50. Spring MD, Chelimo K, Tisch DJ, Sumba PO, Rochford R, Long CA, Kazura JW, Moormann AM: Allele-specificity of IFN-\{gamma\} Responses to the Carboxyl Terminal Region of Plasmodium Falciparum Merozoite Surface Protein 1 by Kenyan Adults with Naturally Acquired Immunity to Malaria. Infect Immun 78:4431-4441.

51. Akanmori BD, Afari EA, Sakatoku H, Nkrumah FK: A longitudinal study of malaria infection, morbidity and antibody titres in infants of a rura community in Ghana. Trans R Soc Trop Med Hyg 1995, 89:560-561.

52. Afari EA, Appawu M, Dunyo S, Baffoe-Wilmot A, Nkrumah FK: Malaria infection, morbidity and transmission in two ecological zones Southern Ghana. Afr J Health Sci 1995, 2:312-315.

53. Nebie I, Diarra A, Ouedraogo A, Soulama I, Bougouma EC, Tiono AB Konate AT, Chilengi R, Theisen M, Dodoo D, et al: Humoral responses to Plasmodium falciparum blood-stage antigens and association with incidence of clinical malaria in children living in an area of seasonal malaria transmission in Burkina Faso, West Africa. Infect Immun 2008, 76:759-766.

54. Dent AE, Bergmann-Leitner ES, Wilson DW, Tisch DJ, Kimmel R, Vulule J, Sumba PO, Beeson JG, Angov E, Moormann AM, et al: Antibody-mediated growth inhibition of Plasmodium falciparum: relationship to age and protection from parasitemia in Kenyan children and adults. PLoS One 2008, 3:e3557.

55. Dodoo D, Aikins A, Kusi KA, Lamptey $H$, Remarque E, Milligan $\mathrm{P}$, Bosomprah S, Chilengi R, Osei YD, Akanmori BD, et al: Cohort study of the association of antibody levels to AMA1, MSP119, MSP3 and GLURP with protection from clinical malaria in Ghanaian children. Malar J 2008, 7:142.

56. Dodoo D, Atuguba F, Bosomprah S, Ansah NA, Ansah P, Lamptey H, Egyir B, Oduro AR, Gyan B, Hodgson A, et al: Antibody levels to multiple malaria vaccine candidate antigens in relation to clinical malaria episodes in children in the Kasena-Nankana district of Northern Ghana. Malar J 10:108.

57. Osier FH, Fegan G, Polley SD, Murungi L, Verra F, Tetteh KK, Lowe B, Mwangi T, Bull PC, Thomas AW, et al: Breadth and magnitude of antibody responses to multiple Plasmodium falciparum merozoite antigens are associated with protection from clinical malaria. Infect Immun 2008, 76:2240-2248.

58. Reece WH, Plebanski M, Akinwunmi P, Gothard P, Flanagan KL, Lee EA, Cortina-Borja M, Hill AV, Pinder M: Naturally exposed populations differ in their T1 and T2 responses to the circumsporozoite protein of Plasmodium falciparum. Infect Immun 2002, 70:1468-1474.

59. Nardin EH, Calvo-Calle JM, Oliveira GA, Nussenzweig RS, Schneider M, Tiercy JM, Loutan L, Hochstrasser D, Rose K: A totally synthetic polyoxime malaria vaccine containing Plasmodium falciparum $B$ cell and universal $T$ cell epitopes elicits immune responses in volunteers of diverse HLA types. J Immunol 2001, 166:481-489.

60. Lockyer MJ, Marsh K, Newbold Cl: Wild isolates of Plasmodium falciparum show extensive polymorphism in T cell epitopes of the circumsporozoite protein. Mol Biochem Parasitol 1989, 37:275-280.

61. Good MF, Pombo D, Quakyi IA, Riley EM, Houghten RA, Menon A, Alling DW, Berzofsky JA, Miller LH: Human T-cell recognition of the circumsporozoite protein of Plasmodium falciparum: immunodominant T-cell domains map to the polymorphic regions of the molecule. Proc Natl Acad Sci USA 1988, 85:1199-1203.

62. Kumar S, Miller LH, Quakyi IA, Keister DB, Houghten RA, Maloy WL, Moss B, Berzofsky JA, Good MF: Cytotoxic T cells specific for the circumsporozoite protein of Plasmodium falciparum. Nature 1988, 334:258-260.

63. Jiang G, Charoenvit Y, Moreno A, Baraceros MF, Banania G, Richie N, Abot S, Ganeshan $\mathrm{H}$, Fallarme $\mathrm{V}$, Patterson NB, et al: Induction of multi-antigen multi-stage immune responses against Plasmodium falciparum in rhesus monkeys, in the absence of antigen interference, with heterologous DNA prime/poxvirus boost immunization. Malar J 2007, 6:135.

64. Wang R, Doolan DL, Le TP, Hedstrom RC, Coonan KM, Charoenvit Y, Jones TR, Hobart P, Margalith M, Ng J, et al: Induction of antigen-specific cytotoxic T lymphocytes in humans by a malaria DNA vaccine. Science 1998, 282:476-480

65. Wang R, Epstein J, Charoenvit Y, Baraceros FM, Rahardjo N, Gay T, Banania JG, Chattopadhyay $R$, de la Vega $P$, Richie $T L$, et al: Induction in humans of CD8+ and CD4+ T cell and antibody responses by sequential immunization with malaria DNA and recombinant protein. J Immunol 2004, 172:5561-5569.

66. Doolan DL, Dobano C, Baird JK: Acquired immunity to malaria. Clin Microbiol Rev 2009, 22(1):13-36, Table of Contents.

67. Crompton PD, Kayala MA, Traore B, Kayentao K, Ongoiba A, Weiss GE, Molina DM, Burk CR, Waisberg M, Jasinskas A, et al: A prospective analysis of the $A b$ response to Plasmodium falciparum before and after a malaria season by protein microarray. Proc Natl Acad Sci USA 107:6958-6963.

68. Doolan DL, Mu Y, Unal B, Sundaresh S, Hirst S, Valdez C, Randall A, Molina D, Liang $X$, Freilich DA, et al: Profiling humoral immune responses to P. falciparum infection with protein microarrays. Proteomics 2008, 8:4680-4694.

doi:10.1186/1475-2875-10-168

Cite this article as: Dodoo et al: Measuring naturally acquired immune responses to candidate malaria vaccine antigens in Ghanaian adults. Malaria Journal 2011 10:168.

\section{Submit your next manuscript to BioMed Central and take full advantage of:}

- Convenient online submission

- Thorough peer review

- No space constraints or color figure charges

- Immediate publication on acceptance

- Inclusion in PubMed, CAS, Scopus and Google Scholar

- Research which is freely available for redistribution

Submit your manuscript at www.biomedcentral.com/submit
C Biomed Central 